\title{
De historiografías y militancias. Izquierda, artiguismo y cuestión agraria en el Uruguay (1950-1973)
}

\author{
Wilson González Demuro
}

Universidad de la República, Montevideo

En el Uruguay, a lo largo del siglo XX todas las fuerzas políticas, sin excepción, han hecho un sostenido uso político de la principal figura histórica del país, José Artigas, uno de los conductores del proceso revolucionario que sacudió al Río de la Plata entre 1810 y 1820. Desde 1950, y hasta el inicio de la dictadura militar en 1973, las izquierdas llevaron adelante una doble operación de rescate y apropiación de Artigas y su revolución, en el marco de un proceso de agitación social y política sin precedentes, que para muchos parecía poner al país al borde de la revolución. En este contexto, algunas escuelas historiográficas cuyos miembros se vincularon más o menos claramente con estos partidos y movimientos izquierdistas, publicaron una serie de estudios que de alguna manera reforzaban el concepto de que la verdadera tradición artiguista arraigaba en estas fuerzas revolucionarias, y no en los llamados "partidos tradicionales", a los que veían más bien como continuadores históricos de la obra de los enemigos de José Artigas.

PALABRAS ClAVE: Uruguay, 1950-1973, historia e historiografía, cuestión agraria, artiguismo.

In Uruguay, throughout the XX century all political forces, without exception, made a sustained political use of the main historical figure of the country, José Artigas, who was one of the leaders of the revolutionary process that shook the Rio de la Plata region between 1810 and 1820. From 1950 up to the beginning of the military dictatorship in 1973, the left carried out a rescue operation and appropriation of Artigas and his revolution. Within the framework of a process of social and political agitation without precedents, many people thought that the country was on the verge of revolution. In this context, some historians who belonged officially or unofficially to these leftist parties and movements, published a series of studies that somehow reinforced the concept that the true artiguista tradition was rooted in their revolutionary forces, not in the traditional political parties. Moreover, they considered them as followers of the work of the enemies of José Artigas.

KeYwords: Uruguay, 1950-1973, history and historiography, agrarian isuues, the legacy of Artigas.

"El pasado puede verse como prototipo de nuestra propia época o, por otro lado, como una era diferente a causa de las erosiones y los acrecentamientos

de sus propios restos. La elección de la perspectiva afecta no sólo a lo que decidimos recordar o conservar, sino a cómo distinguimos el pasado del presente"

DAVID LOWENTHAL ${ }^{1}$

1 Lowenthal, David: El pasado es un país extraño, Madrid, Akal, 1998, pág. 267. El autor agradece los comentarios hechos a versiones preliminares de este trabajo por los Dres. Jorge Daniel Gelman y Juan Antonio Oddone. 


\section{Introducción}

En Uruguay, desde mediados del siglo XX hasta la dictadura militar iniciada en 1973, las fuerzas políticas de izquierda promovieron vigorosamente la recuperación histórica de la figura de José Artigas y del proceso insurreccional por él conducido entre 1811 y 1820 . Estas organizaciones (algunas nacidas durante esos años, otras a comienzos de siglo) encontraron en el artiguismo - con distintos matices - un interlocutor idóneo en tanto se lo caracterizó como un movimiento revolucionario, independentista, democrático y antiimperialista, condiciones con las que esas fuerzas se autoidentificaban. Sin distinción, ${ }^{2}$ todas ellas enarbolaron el estandarte del artiguismo y, de acuerdo a sus perfiles ideológicos y metodologías de lucha, tendieron a destacar determinados aspectos de aquel proceso. El uso político del artiguismo, siempre presente en la praxis de la izquierda, alcanzó sus niveles más altos en esa coyuntura.

El terreno del conocimiento histórico (lo cual incluye tanto el ámbito académico "profesional" como el amateur) fue también un sitio privilegiado para llevar adelante la lucha de ideas, confirmando una vez más que el campo de acción de esta disciplina no constituye una "zona neutral". Nuevas miradas sobre facetas del artiguismo anteriormente transitadas por la historiografía, y la exploración de otras perspectivas hasta entonces poco atendidas, dieron el tono a una porción muy considerable de los estudios sobre el pasado uruguayo. Se entabló a partir de mediados del siglo XX una dura lucha entre la vieja concepción "oficial" del artiguismo, según la cual este movimiento puso los cimientos del Uruguay como nación independiente y republicano-democrática (la "leyenda celeste" acuñada por el liberalismo a finales del siglo XIX y comienzos del XX, opuesta a su vez a la anterior "leyenda negra" elaborada por los adversarios de Artigas ${ }^{3}$ ), y una nueva visión que buscó poner al descubierto sus facetas revolucionarias y

2 Una aproximación a la manera específica en que la guerrilla tupamara pretendió asumir las enseñanzas históricas del artiguismo fue publicada hace algunos años. Ver González, Wilson: "Sobre el uso público de la historia: José Artigas en la visión del Movimiento de Liberación Nacional-Tupamaros, 1965-1972”, en Desmemoria, n. ${ }^{\circ} 11$, Buenos Aires, junio-agosto de 1996 (que es a su vez un resumen de El artiguismo en la visión del MLN -T, inédito, 1995). Algunas ideas de estos trabajos son retomadas aquí.

3 Algunos aportes fundamentales (no los únicos, por cierto) a esa construcción fueron las obras de de María, Isidoro: Vida del Brigadier General D. José Jervasio Artigas, fundador de la nacionalidad oriental [sic], 1860; Ramírez, Carlos María: Artigas, 1884; Fregeiro, Clemente: Artigas. Estudio histórico. Documentos justificativos, 1886; Zorrilla de San Martín, Juan: La Epopeya de Artigas, 1907; Pereda, Setembrino: Artigas, 1764-1850, 1930. 
populares. El costado agrarista del proceso abierto en 1811 fue uno de los elementos que mejor captó, por un lado, el interés de quienes vieron allí un nuevo campo de estudio para una disciplina histórica que deseaba renovarse (estableciendo nuevas formas de diálogo con la realidad social en la que estaba inmersa). Pero, por otra parte, hubo también quienes, manifestando un interés político más definido, se acercaron al agrarismo artiguista para encontrar allí no solamente un fenómeno históricamente localizado y analizable como tal, sino una suerte de preámbulo inspirador (¿tal vez, para algunos, un modelo?) de la revolución popular que parecía aproximarse. Se generó pues un movimiento literario e historiográfico de ribetes muy definidos y capaz de alimentar la idea de que una nueva leyenda, esta vez "roja", había nacido. ${ }^{4}$

Toda una zona "olvidada" del artiguismo, precisamente la que había resultado derrotada luego de 1820 (fundamentalmente sus programas federal y agrario), ocupó nuevamente el centro de atención académica y política. Los movimientos sociales y políticos, generados y potenciados al calor de la crisis inaugurada en la posguerra, salieron al encuentro de un pasado revolucionario del que también se nutrieron para su acción. Así, esta memoria "no oficial" de la historia uruguaya, en confrontación con la "oficial" buscó dar un nuevo giro al concepto y al contenido de la memoria colectiva e incidió (en grado difícilmente mensurable y pendiente de necesario estudio, pero probablemente alto) en las prácticas políticas colectivas de la izquierda. "Sin invocar memorias colectivas de este tipo sería difícil explicar la geografía de la contestación y la protesta"; la afirmación es de Peter Burke, y resulta, como se verá, muy adecuada al caso que nos ocupa. ${ }^{5}$ Una historia relacionada, en cierto modo aliada, con el proceso de construcción de un imaginario social alternativo, apoyada en términos generales en un discurso opuesto al de los sectores socialmente dominantes en el país y que respaldaban las más tradicionales visiones del artiguismo, en la línea de la ya aludida "leyenda celeste". Tomás Sansón ha hecho una propuesta interesante para el estudio de estos debates, que adapta los

4 Yaffé, Jaime: "La izquierda uruguaya y el pasado revolucionario oriental. ¿Una leyenda roja del artiguismo?", en Frega, Ana, e Islas, Ariadna (coords.): Nuevas miradas en torno al Artiguismo, Montevideo, Departamento de Publicaciones de la Facultad de Humanidades y Ciencias de la Educación (UDELAR), 2001. Para este autor (ver págs. 416 y 422, n. 6), el proceso de rescate del artiguismo por parte de la izquierda se manifestó con claridad a partir de mediados de la década de 1960. Aquí se intentará demostrar además que el origen de dicha operación es anterior.

5 "La historia como memoria colectiva", en Burke, Peter: Formas de historia cultural, Madrid, Alianza, 2000, pág. 81. 
planteos de Roland Barthes y se basa en la aplicación de las categorías encrático y acrático a los diferentes discursos historiográficos, emitidos desde el poder y desde afuera del mismo, respectivamente. ${ }^{6}$ En cierta medida, este trabajo dará cuenta de la construcción de un discurso "acráticoagrarista" (permítase el neologismo) de parte de la izquierda.

A través del examen de varias obras publicadas en el lapso 19501973, se puede establecer de qué modo las opciones temáticas, teóricas y metodológicas - en especial en lo que atañe a los estudios sobre artiguismo y cuestión agraria- se articularon con inquietudes y proyectos sociopolíticos de la izquierda en aquella hora.

\section{El contexto cultural. Uruguay luego de 1950}

\section{a) La percepción de la crisis}

El llamado "Uruguay feliz" comenzó a dar señales de agotamiento pocos años después de finalizada la Segunda Guerra Mundial; los indicadores socioeconómicos se fueron deteriorando, y al compás de esa declinación la situación política se agravó progresivamente hasta consumarse el quiebre institucional de 1973. La literatura al respecto es ya bastante abundante, por lo que no es del caso entrar en el análisis de la coyuntura, sino recordar solamente algunos aspectos claves en nuestro estudio.?

Hasta allí, la idea de la "excepcionalidad uruguaya" se había montado sobre cuatro "mitos consolidados": el de la medianía (validez de un modelo social sustentado en la mesocracia y el asistencialismo estatal), el de la diferenciación (notablemente resumido en un eslogan muy popular en esos tiempos: "como el Uruguay no hay"), el del consenso, "el de la ley

6 Sansón, Tomás: Aproximación a la historiografía marxista uruguaya en la década de 1960, ponencia ante el seminario "Problemas y desafíos de la historiografía rioplatense (1950-1975)", Facultad de Humanidades y Ciencias de la Educación (UDELAR)-Departamento de Historiología, Montevideo, 16 y 17 de noviembre de 2001; "La guerra de los lenguajes", en Barthes, Roland: El susurro del lenguaje. Más allá de la palabra y la escritura, Barcelona, Paidós, 1994.

7 Algunas aproximaciones: D’Elia, Germán: El Uruguay neo-batllista (1946-1958), Montevideo, EBO, 1982; Alonso, Rosa, y Demasi, Carlos: Uruguay, 1958-1968. Crisis y estancamiento, Montevideo, EBO, 1986; Cancela, Walter, y Melgar, Alicia: El desarrollo frustrado. 30 años de economía uruguaya (1955-1985), Montevideo, CLAEH-EBO, 1985, págs. 12-46; Varela, Gonzalo: De la república liberal al estado militar. Crisis política en Uruguay, 1968-1973, Montevideo, Nuevo Mundo, 1988; Zubillaga, Carlos: "Los partidos políticos ante la crisis (1958-1973)", en AA.VV.: De la tradición a la crisis. Pasado y presente de nuestro sistema de partidos, Montevideo, CLAEH-EBO, 1991. 
impersonal que se impone", y por último (un mito sobre el cual aún hoy se insiste hasta el patetismo), el de la existencia de una población con un nivel cultural medio muy elevado. ${ }^{8}$

Pero terminada la etapa de aprovechamiento del clima bélico mundial, que en Uruguay tuvo una fugaz continuación con los beneficios acarreados por la Guerra de Corea, llegó la hora de los balances en rojo. En el nuevo escenario, se hizo tarea ineludible (incluso entre quienes solían mantenerse puntualmente fuera de todos los debates de ideas) la exploración más detenida de los temas de la "conciencia de la circunstancia (temporal y espacial; nacional, regional, universal)", sobre la que escribiera Carlos Real de Azúa. ${ }^{9}$ Resultado de ello fueron numerosos diagnósticos poblados de ásperas críticas. Si en años anteriores el mito de la "excepcionalidad uruguaya" era una suerte de seguro contra los cataclismos de todo pelo que asolaban América, en la nueva etapa constituía una barrera contra los intentos de cambio. Lo que antes era confiada placidez, era ahora mediocridad desembozada; al "orgullo de lo que se tiene" se oponía la acusación de conformismo provinciano. ${ }^{10} \mathrm{El}$ blanco predilecto de la crítica intelectual fue "la crisis" (en el sentido más lato posible), lo que no excluía a los propios intelectuales.

El escritor y crítico literario Angel Rama les reclamaba en 1965 una nueva actitud, "que libere al país de la atonía presente, y abra las vías para una nueva sociedad [superando] la fragmentación, el poco vuelo, la demora en formas tradicionales". Culminaba con una aguda reflexión y un deseo: "una lección [de un] libro de lectura infantil ha pesado sobre la cultura uruguaya. Decía aquel texto de Abadie-Zarrilli, ${ }^{11}$ sin sospechar que adelantaba una interpretación simbólica de la nación: 'Mis zapatos tienen la suela vieja. No voy al patio, así no me mojo los pies. Me siento junto a

8 Rial, Juan: "El 'imaginario social' uruguayo y la dictadura. Los mitos políticos de (re)construcción”, en Perelli, Carina, y Rial, Juan: De mitos y memorias políticas, Montevideo, EBO, 1986, págs. 22-24.

9 Real de Azúa, Carlos: Antología del ensayo uruguayo contemporáneo, tomo I, Montevideo, Departamento de Publicaciones de la UDELAR, 1964, pág. 44. El subrayado es de Real.

10 Véase un buen resumen del "malestar de la cultura" a finales de los 60 en Real de Azúa, Carlos: El Uruguay como reflexión (I), Capítulo Oriental, n. ${ }^{\circ}$ 36, Montevideo, Centro Editor de América Latina, 1969. También es recomendable la consulta de Rama, Ángel: La generación crítica (1939-1969), Montevideo, Arca, 1972.

11 Entre las décadas de 1920 y 1930 Roberto Abadie Soriano y Humberto Zarrilli publicaron por encargo de las autoridades educativas, una serie de manuales de lectura ampliamente difundidos en nuestras escuelas. Su contenido influyó considerablemente en la formación y consolidación de la mentalidad de varias generaciones de uruguayos. Sus títulos eran reveladores: Alegría, Tierra Nuestra, Campo, Patria, Uruguay, Optimismo, etc. 
la mesa y estudio. La lluvia me da sueño. ¿Qué linda siesta si no viene nadie!'. Lamentablemente [...] alguien vino, y la voraz crisis en que nos estamos moviendo parecería esbozar el rostro de una 'anciana dama' inquietante. Bienvenida sea". ${ }^{12}$

\section{b) Un tema clave: protagonismo en alza de la cuestión agraria}

Uruguay comenzó a discutir con mayor intensidad el problema de sus estructuras agrarias al concluir la Segunda Guerra Mundial. Siendo un país históricamente recostado en el sector primario de la economía, no era aquella una discusión de segundo orden. De lo que se trataba era del agravamiento de una serie de inconvenientes cuyos orígenes se ubicaban varias décadas más atrás: concentración de la propiedad de la tierra, una producción agropecuaria estancada y en constante fricción con la más reciente industrialización urbana, ${ }^{13}$ atraso tecnológico, permanente tránsito de pequeños productores empobrecidos desde el campo a las ciudades (especialmente a Montevideo), endeudamiento y pauperización de los que lograban quedarse, etc. Ciertos aspectos de larga duración de esa siempre asimétrica relación entre sociedad urbana y sociedad rural ganaron un protagonismo inédito en los debates económicos y políticos.

Empeoraba las cosas el hecho de que, según opinión de amplios sectores de la vida rural, estos delicados asuntos eran invariablemente descuidados u olímpicamente ignorados por la dirigencia urbana. Se escucharon voces de alerta: algunos dirigentes políticos vinculados al sector ganadero hicieron notar en 1944 que una sociedad estancada y empobrecida como la rural, ofrecía al comunismo un terreno fértil para su prédica, lo que imponía la necesidad de actuaciones decididas a favor del sector agropecuario. ${ }^{14}$ La experiencia del "Ruralismo" — movimiento político y gremial conducido por Benito Nardone en la posguerra— logró, más allá de su cerrado anticomunismo y final absorción por el sistema político tradicional, poner obstáculos al proyecto industrialista del batllismo y hacer visible la magnitud

12 Rama, Ángel: "Del provincianismo cultural”, en Real de Azúa, Carlos: (ed.): El Uruguay visto por los uruguayos (I), Montevideo, Centro Editor de América Latina, 1968, págs. 154-160.

13 Ver una síntesis de estos enfrentamientos hacia fines de la guerra mundial en Frega, Ana; Maronna, Mónica, y Trochon, Yvette: Baldomir y la restauración democrática (1938-1946), Montevideo, EBO, 1987, págs. 69-80.

14 Chiarino, Juan V., y Saralegui, Miguel: Detrás de la ciudad. Ensayo de síntesis de los olvidados problemas campesinos, Montevideo, Impresora Uruguaya, 1944. 
de ciertos viejos problemas en el medio rural, y las posibilidades de movilización de sus habitantes. ${ }^{15}$

Al avanzar la década de 1960, se buscó afrontar con criterios nuevos una crisis que parecía tornarse inmanejable. Adquirieron mayor protagonismo los equipos técnicos multidisciplinarios, que realizaron a pedido del gobierno nacionalista extensos estudios cuyas recomendaciones finales prácticamente no fueron atendidas. ${ }^{16}$ Para la izquierda era muy claro que la raíz de los problemas nacionales estaba en las estructuras agrarias, particularmente en una distribución injusta de la tierra tan antigua como la propia existencia de estancias en este territorio. En una obra trascendente para el campo socialista uruguayo, escrita en 1958 y publicada como libro dos años después, Vivián Trías, importante dirigente y uno de los muchísimos militantes de izquierda que se ocupó del asunto, señaló que mientras no se determinaran los motivos históricos por los cuales "poco más de mil propiedades [acumulaban] aproximadamente, el 35\% de la superficie explotable del Uruguay [...] una espesa bruma [cubriría] las causas profundas y reales de los más graves problemas" existentes. ${ }^{17}$ Para este autor una de las soluciones de fondo estaba, sin ninguna clase de dudas, en la reforma agraria, idea que ganaba terreno velozmente en la izquierda. Proliferaron escritos de todo tenor sobre este tema. Uno de ellos, preparado por José Luis Durán, planteó la cuestión en términos muy llanos en 1968, al expresar que "el país no puede perder más tiempo, está al borde del abismo y la reforma agraria lo salva con toda seguridad". ${ }^{18}$

15 Sobre Nardone y su movimiento "Ruralista", véase Jacob, Raúl: Benito Nardone: el Ruralismo hacia el poder (1945-1958), Montevideo, EBO, 1981. Zubillaga: "Los partidos políticos...”, págs. 41-48.

16 En 1965, la Comisión de Inversiones y Desarrollo Económico (CIDE, creada en 1960), de matriz cepalina, publicó su Plan de Desarrollo Económico y Social; un poco antes, en 1963, otro equipo integrado por investigadores franceses y del Centro Latinoamericano de Economía Humana (CLAEH) publicó, con apoyo del Ministerio de Ganadería y Agricultura, su Situación económica y social del Uruguay rural. En ambos, se formulaban críticas a los vicios e insuficiencias de las estructuras agrarias vigentes. Zubillaga comenta que esta nueva estrategia del gobierno fue "un intento por desplazar hacia el campo científico la búsqueda de 'recetas' que su propia indefinición ideológica le impedía formular por sî" (en "Los partidos políticos...", pág. 54).

17 Trías, Vivián: Reforma agraria en el Uruguay, Montevideo, El Sol, 1960, citado en Trías, Vivián: La crisis agraria y el socialismo en el Uruguay (selección de textos y prólogo a cargo de Martín Buxedas), Montevideo, EBO, 1990, pág. 89.

18 Durán, José Luis: Por un Uruguay mejor, tomo II, «Reforma Agraria», Montevideo, s/e, 1968, pág. 360. Esta monografía es un verdadero esfuerzo militante: editada por su propio autor, que confesaba desconocer cuestiones técnicas (pese a lo cual todo el tomo apunta a definir qué es y cómo se hace una reforma agraria), sorprende al lector de hoy por la candidez de ciertas afirmaciones. Un ejemplo: "este libro adolece de muchos vacíos y repeticiones, porque no ha sido corregido. [...] Había que escribir algo, aunque fuera malo, para incitar a otros más capacitados a hacerlo" (pág. 19). Aunque todo esto puede con justicia ser catalogado de voluntarismo extremo y autoconsciente, da una pauta de la capacidad de convocatoria que este debate poseía en la izquierda uruguaya. 
Precisamente, por la izquierda ganó espacios una nueva forma de organización social hasta entonces poco considerada entre los uruguayos: el sindicalismo rural. En los años 50, resume con precisión Gonzalo Varela, "la campaña fue a la ciudad como obrero, pero la ciudad también fue al campo como sindicalista". ${ }^{19}$ Particularmente los partidos marxistas (socialistas y comunistas) habían hecho esfuerzos por trascender sus habituales ámbitos urbanos organizando gremios entre los peones rurales; pero en los años 60 el movimiento adoptó un perfil nuevo y más combativo al influjo de planteos ideológicos y metodologías radicales, que vinieron a poner seriamente en duda los conceptos hasta entonces vigentes sobre la "pasividad" de la campaña. ${ }^{20}$

Las percepciones negativas sobre la situación rural no solamente arraigaban en esta franja del espectro político: un destacado funcionario del gobierno nacionalista se refirió por entonces a lo que llamó "círculos viciosos del estancamiento" nacional: parálisis de la producción (originada en la agropecuaria, y continuada en la industria), depresión de la capacidad de pago, inflación y desempleo. ${ }^{21}$

\section{Artigas, cuestión agraria e historiografía de izquierda, 1950-1973}

Aunque no todos los reparos al denunciado quietismo que había ganado al país fueron necesariamente emitidos por individuos y grupos de izquierda, tratándose de sectores tradicionalmente opositores fue naturalmente allí donde más se alzaron las voces de alarma. Por añadidura, esta serie de cuestionamientos al presente y a la imagen que del pasado había edificado la sociedad uruguaya trajo consigo la introducción de notorios cambios en el plano de la historiografía. El escenario ideal para que ciertos hechos y procesos de nuestro pasado cobraran indisputado interés, estaba preparado.

19 Varela: De la república liberal..., pág. 73.

20 En este proceso los sectores de la izquierda radical tuvieron gran protagonismo. Raúl Sendic, principal dirigente tupamaro, participó activamente en la organización de los sindicatos de trabajadores azucareros y arroceros del norte y noreste del país. Para una aproximación a la problemática del sindicalismo rural, y especialmente de las organizaciones en las que Sendic tuvo gravitación, ver González, Yamandú: Los olvidados de la tierra, Montevideo, Nordan, 1994, capítulos IV, VIII y X, y Moraes, María Inés: Bella Unión: de la estancia tradicional a la agricultura moderna (1863-1965), Montevideo, CINVE-EBO, 1990, págs. 227-240.

21 Iglesias, Enrique: Uruguay: una propuesta de cambio, Montevideo, Alfa, 1966, págs. $37-$ 39. Iglesias es actualmente presidente del Banco Interamericano de Desarrollo. 


\section{Dos precisiones previas}

Un par de preguntas necesariamente previas deben ser respondidas en forma breve en este apartado.

1. En primer lugar, ¿qué implica hablar de la cuestión agraria? La primera imagen que surge es la de una amplia y compleja articulación de elementos vinculados a la vida rural, desde los más puramente económicos a los específicamente sociales. En un sentido más estricto, la materia de la cuestión agraria es la estructura agraria (con sus fuerzas productivas y relaciones de producción características), y una extensa y variada gama de problemas que le son propios. Un menú amplio aunque seguramente no exhaustivo incluye: formas de acceso a la posesión de tierras, cuestiones ecológicas, tipos de producción, distribución y circulación, patrones de inversión y formas de extracción de beneficios, fuerzas de trabajo operantes (tipos, desarrollo e interrelaciones), factores socio-demográficos (familia, aspectos étnicos, migraciones, asentamientos fronterizos), culturales (religión, tradiciones, niveles educativos), elementos de orden político (sistemas de lealtades, caudillismos, rebeliones, revoluciones y contrarrevoluciones en el campo), etc. Semejante multiplicidad (enriquecida por el peso de las variables "espacio" y "tiempo") invita a delimitar "cuestiones" o "subcuestiones agrarias", diversificando los análisis. No es ocioso recordar que el transitado recurso al diccionario es útil también en este caso: el vocablo cuestión alude tanto a un "asunto o materia en general" como a un "punto o materia dudosos o discutibles".

Al razonable objetivo de alcanzar interpretaciones panorámicas se opone una dificultad: un corte temático excesivamente amplio puede resultar tan atractivo como inabarcable. Para Cardoso y Pérez Brignoli, sería necesaria "la existencia previa de materiales disponibles tan numerosos y variados [que su tratamiento] a corto plazo, salvo en un nivel modesto geográfica y cronológicamente, sería poco menos que imposible en países de América Latina". ${ }^{22}$ Esto es lo que hace de los estudios monográficos de base mojones indispensables en el camino hacia la construcción de explicaciones globales. Insoslayable es al mismo tiempo la necesidad que la historia agraria tiene de apoyarse en (y apoyar a) otras ciencias sociales en

22 Cardoso, Ciro F.S., y Pérez Brignoli, Héctor: Historia económica de América Latina, tomo I, Barcelona, Crítica, 1979, pág. 14. 
general, y otras subramas del quehacer historiográfico en particular: la historia económica, la historia del derecho y las instituciones jurídicas, la historia social, la historia de las mentalidades, la geografía histórica y la archivología. ${ }^{23}$

Esta rama de la historiografía no es inmune a los riesgos. Existe entre algunos historiadores la tentación de confundir los temas de historia agraria con la historia misma. Emmanuel Le Roy Ladurie, por ejemplo, ha definido como uno de sus objetos de estudio la "civilización rural". Esto ha generado controversias. ${ }^{24}$ Pierre Vilar, hace más de dos décadas, advertía sobre los riesgos implícitos en esta inclinación al "aislacionismo", en buena medida derivada de una delimitación errónea (por el excesivo poder explicativo que se le adjudica) del concepto de campesinado ${ }^{25}$ La literatura posterior ha intentado superar esta dificultad. Reconocida la importancia de encuadrar la cuestión agraria en un escenario mucho más vasto, ${ }^{26}$ se apeló a modelos alternativos, como el de la articulación de diferentes modos de producción coexistentes, donde el medio agrario se integra en un mosaico más engorroso tal vez, pero por lo mismo (y aunque parezca paradójico) más inteligible. Algunos trabajos de Eric Van Young son ejemplares al respecto. ${ }^{27}$

Para concluir este punto: la reciente producción historiográfica sobre cuestiones agrarias en el Río de la Plata entre los siglos XVII y primera mitad del XIX ha aceptado el reto multidisciplinario, de lo que resultó una importante cantidad de estudios sobre aspectos muy diversos cuyo ritmo de aparición se ha acelerado en las últimas dos déca-

23 Marín, Fermín: "Historia Agraria de la España Moderna: evolución y tendencias recientes", en Actas del II Coloquio internacional de historiografía europea: la historia de Europa hoy, Facultad de Humanidades - Universidad de Mar del Plata, 1999.

24 Es dudosa la funcionalidad del concepto "civilización rural"; objetando el planteo de Le Roy Ladurie, François Dosse considera peligroso sobredimensionar las especificidades del mundo agrario, haciéndolo marchar en paralelo a la "civilización urbana" como si efectivamente se tratase de dos culturas absolutamente independientes. Dosse, François: La historia en migajas, Valencia, Edicions Alfons el Magnánim, 1988, págs. 183-184.

25 Vilar, Pierre: “Economía campesina?” (1978), en Iniciación al vocabulario del análisis histórico, Barcelona, Crítica, 1982. Otros aportes marxistas a la discusión sobre los conceptos de "campesinado" y "cuestión agraria" suscitada entre las décadas de 1960 y 1970, en Hobsbawm, Eric: Los campesinos y la política, Barcelona, Anagrama, 1976, y Godelier, Maurice: Las sociedades precapitalistas, México, Quinto Sol, 1978.

26 Dandler, Jorge: "La estructura agraria en América Latina. Un modelo de análisis", en Revista Mexicana de Sociología, 38:1, México DF, enero-marzo, 1976.

27 Véase su breve pero excelente artículo: Van Young, Eric: "Sectores medios rurales en el México de los Borbones: el interior de Guadalajara en el siglo XVIII", en HISLA. Revista Latinoamericana de Historia Económica y Social, n. ${ }^{\circ}$ 8, Lima, segundo semestre, 1986. 
das. ${ }^{28}$ Sin embargo, el desarrollo no ha sido simétrico; es en la Argentina donde la renovación de estos estudios ha calado más hondo. En el Uruguay, aunque las excepciones siempre existen, ${ }^{29}$ la falta de renovación es la única consecuencia posible del desinterés por estos temas. María Inés Moraes destaca el "angustioso silencio" que rodea la investigación en historia agraria uruguaya, afectada por "un abandono tan apresurado como unánime", a partir del cual ha sido "desaprovechado tanto en sus logros como en sus tropiezos" el empuje experimentado por estos estudios en el país vecino. ${ }^{30}$ Carencia de preocupaciones por lo agrario que no era, por cierto, un elemento que caracterizara a la historiografía de los años 50, 60 y tempranos 70 .

2. La segunda pregunta previa es: ¿qué significaba ser historiador y a la vez "ser de izquierda" antes de 1973? Admítase de entrada que cada individuo es una complicada articulación de lo que es (suponiendo, con exceso de optimismo tal vez, que se pueda "ser" objetivamente), lo que cree ser y lo que los demás (un "ellos" no unánime) creen que es, por lo que el terreno se torna resbaladizo y cualquier respuesta resultará por fuerza cuestionable. Se deja de lado aquí la inacabable polémica sobre la validez de las categorías "izquierda - derecha", sobre cuya existencia, en verdad, en plena Guerra Fría no muchos discutían, aunque sí lo hacían sobre los contenidos de cada concepto; con todas las numerosas salvedades que sin duda puedan oponerse, se intentará fijar algunos mínimos criterios de identificación.

28 Tres balances de resultados: Di Stefano, Roberto: "El mundo rural rioplatense colonial: una cuestión abierta", en Boletín del Instituto de Historia Argentina y Americana "Dr. Emilio Ravignani", 3. ${ }^{a}$ serie, n. ${ }^{\circ}$ 4, 2do. Semestre, 1991, y dos trabajos de Garavaglia, Juan Carlos, y Gelman, Jorge Daniel: "Rural History of the Río de la Plata, 1600-1850: Results of a Historiographical Renaissance", en Latin American Research Review, 30:3, 1995; y "Mucha tierra y poca gente: un nuevo balance historiográfico de la historia rural rioplatense (1750-1850)", en Historia Agraria, 15, Murcia, 1998.

29 Son escasos los aportes significativos (investigaciones o ensayos) que se aproximan más o menos directamente, y desde perspectivas muy diversas, a estos asuntos. Entre lo publicado desde mediados de los años 80 hasta hoy, cabe destacar Jacob, Raúl: "Los principales modelos históricos", en AA. VV.: La cuestión agraria en el Uruguay, Montevideo, FCU, 1984, págs. 7-23; Casal, Juan Manuel: El modo de producción colonial en el Río de la Plata, Montevideo, Nuevo Mundo, 1987. Vázquez Franco, Guillermo: Economía y sociedad en el latifundio colonial, Montevideo, Forum, 1986, dedicado al estudio de la economía agraria entre el final del coloniaje y la segunda mitad del siglo XIX, y Tierra y Derecho en la Rebelión Oriental [a propósito del Reglamento del Año XV], Montevideo, Proyección, 1988, uno de los artículos en los que revisa críticamente el artiguismo. Sala, Lucía, y Alonso, Rosa: El Uruguay comercial, pastoril y caudillesco, Montevideo, EBO, 1986 (tomo 1) y 1991 (tomo 2), extiende al período posrevolucionario el modelo de análisis aplicado a una etapa anterior.

30 Moraes, María Inés: "Dos versiones sobre las transformaciones económicas y sociales del medio rural uruguayo entre 1860-1914", en Cuadernos del CLAEH, n. 83-84, Montevideo, 1999, págs. 216 y 237. 
Por razones de pertinencia, no se profundizará aquí en el estudio de lo que "ser de izquierda" simbolizaba; ${ }^{31}$ simplemente se hará una enumeración de ciertos supuestos compartidos ("comunes denominadores" podría decirse) por quienes con estas opciones se identificaban de modo más o menos pleno. Más allá de una adhesión (ya fuera ad hoc o completa y duradera) a los llamados "partidos de ideas" (socialismo, comunismo, democracia cristiana), o a alguno de los numerosos movimientos autoproclamados izquierdistas nacidos en los años 60, "ser de izquierda" era sinónimo de grados de compromiso variables, aunque casi siempre importantes, con el igualitarismo, la democracia como régimen de participación ampliada, la defensa del intervencionismo estatal en la economía, el sindicalismo, el socialismo (en sus múltiples versiones), el antiimperialismo (en clave fundamentalmente antinorteamericana), y la adhesión manifiesta a ciertas causas, entre las que destacó con nitidez la Revolución Cubana, que parece haber funcionado como un verdadero parteluz para la intelectualidad y la sociedad toda. ${ }^{32}$

\section{Otros tiempos, otras formas de hacer historia}

Entre quienes se sumaron, con intensidad disímil pero inequívoca, a estos partidos y/o movimientos de izquierda e hicieron del quehacer historiográfico uno de sus centros de interés intelectual y profesional, vale destacar (en una lista extensa y con personalidades variadas) a Oscar Bruschera, Roberto Ares Pons, Vivián Trías, Lucía Sala de Touron, Julio Rodríguez, Nelson de la Torre, Eugenio Petit Muñoz, Germán D’Elía,

31 Beisso, Rosario, y Castagnola, José Luis: "Las adhesiones políticas de izquierda en Uruguay. ¿Un caso de politicocentrismo?”, en Cuadernos del CLAEH, n. ${ }^{\circ}$ 49, Montevideo, 1989, y Moreira, Constanza: Democracia y desarrollo en Uruguay, Montevideo, Trilce, 1997, págs. 94-99 y 120 y ss.

$32 \mathrm{El}$ impacto del proceso cubano fue trascendental, o por lo menos así lo creyeron quienes protagonizaron las movilizaciones sociales de entonces. Carlos Machado, a quien encontraremos más adelante en su doble papel de militante socialista e historiador, identificó en el panorama político latinoamericano las siguientes tendencias: la "derecha" (a secas), la "derecha nacionalista", la "izquierda liberal" y la "izquierda tradicional" (socialdemocracia y comunismo "clásico"). Pero luego de 1959, "la revolución victoriosa de Cuba alteró los esquemas pasados", empujando a la radicalización de la derecha —que enfiló hacia "las formas abiertas de la represión"— y las izquierdas — "pulverizó a la izquierda liberal, [...] sacudió al socialismo y a los comunistas, [...] fermentó las nuevas discusiones"- Ver Machado, Carlos: Izquierdas y derechas en América Latina. Documentos, Montevideo, Patria Grande, 1968, págs. 5-6. 
Carlos Zubillaga, Carlos Machado, Luis Carlos Benvenuto, José de Torres Wilson o Alfonso Fernández Cabrelli. Otros autores mantuvieron una independencia que osciló entre las adhesiones inorgánicas y una más notoria (cuando no absoluta) libertad de movimientos: Carlos Real de Azúa, José Pedro Barrán, Benjamín Nahum, Raúl Jacob, Esteban Campal, Guillermo Vázquez Franco, Gustavo Beyhaut, Blanca París de Oddone y Juan Antonio Oddone entre otros, se inscribieron en este segmento. No todos ellos, ciertamente, enfocaron su labor en la cuestión agraria y el artiguismo; pero sí compartieron determinadas pautas de trabajo.

Se desempeñaron fundamentalmente en los ámbitos universitario, de formación docente y de enseñanza secundaria, y lo hicieron en momentos en que estas instituciones procesaron importantes transformaciones, como se verá enseguida. Llevaron a cabo su labor, la mayor parte de ellos, siguiendo determinados patrones que ayudaron (junto con los contenidos de sus obras) a diferenciarlos de investigadores alineados con otras corrientes de pensamiento. Frecuentaron ciertos canales muy característicos: determinados diarios y semanarios (Epoca, Ahora, La Idea, El Sol, El Popular, Marcha, entre otros); revistas (Cuadernos de Marcha, Praxis, Nexo, Estudios, Tribuna Universitaria, Para Todos) o también - ya tratándose de libros- editoriales como Asir, Arca, Ediciones de la Banda Oriental (EBO), Ediciones Pueblos Unidos (EPU), Centro Editor de América Latina, entre las más importantes.

Hubo otros elementos comunes. No solamente estímulos "exteriores" (si por tales entendemos la crisis económica y social, y la agitación política) influyeron sobre la nueva forma de afrontar los estudios sobre el pasado uruguayo y americano transitada por todos estos autores. Como se adelantó más arriba, variantes más bien "internas" — pese a que es siempre difícil establecer hasta qué punto éstas se independizan del acontecer social que las circunda - jugaron un papel decisivo en dicha renovación. La aparición de la Facultad de Humanidades y Ciencias (1945), y su Instituto de Investigaciones Históricas (1947) introdujeron (con fuertes estímulos de parte de algunos de sus docentes) $)^{33}$ cambios profundos en la formación de los historiadores, jerarquizando su función en varios planos. La creación

33 Los casos más notorios: José Luis Romero, Emilio Ravignani y Eugenio Petit Muñoz. Véase al respecto Zubillaga, Carlos: "Entre controversias y consensos. La historiografía uruguaya durante la segunda posguerra mundial. 1945-1956", en Pagano, Nora, y Rodríguez, Martha (comps.): La historiografía rioplatense en la posguerra, Buenos Aires, La Colmena, 2001; y "El Instituto de Investigaciones Históricas y los estudios artiguistas”, en Frega e Islas (coords.): Nuevas miradas... 
(entre 1949 y 1951) del Instituto de Profesores Artigas significó un aporte en el mismo sentido. ${ }^{34}$

Los diferentes grupos de estudio y equipos de investigadores surgidos entonces debatieron acerca del papel que al investigador en historia cabía cumplir ante la nueva realidad uruguaya. La elección de determinados núcleos temáticos les resultó clave para dar mayor visibilidad al esfuerzo por trabar nuevas relaciones con la sociedad en cambio. José Pedro Barrán explicaría en 1970 que en medio de la diversidad de sus concepciones historiográficas les unía "una visión similar — aunque no idéntica- del presente del Uruguay y de la función que a un investigador del pasado le cabe en el 'entender' ese presente. [...] El pasado para aclarar y diagnosticar el presente [...]. En suma, una Historia no aséptica, sino, [...] comprometida". ${ }^{35}$ Precisamente, Barrán integró desde la década de 1960 un grupo denominado "Historia y Presente", junto a varias figuras de esa nueva historiografía "profesional": entre los más notorios, Benjamín Nahum, Juan Oddone, Blanca París, Julio Rodríguez, Lucía Sala, Nelson de la Torre, Luis Carlos Benvenuto y Julio Millot. Todos ellos eran jóvenes docentes, estudiantes avanzados o recientes egresados de los centros mencionados.

En otra cuerda, desarrollando su labor fuera de estos marcos más formales de investigación (aunque no ajenos a las influencias de lo que en ellos se producía) otros autores coincidieron, de diferentes formas, en la necesidad de hurgar en el pasado para dar respuestas a las angustias de aquel presente. Que lo hayan hecho de modos distintos significa que los espacios en que se desempeñaban, su metodología (frecuente recurso al ensayo y una escasa o casi nula exploración en fuentes documentales inéditas), los supuestos teóricos, y hasta los estilos expositivos se caracterizaron por una gran diversidad, la misma que alcanzó —esto debe ser cuidadosamente subrayado - a la propia calidad de los resultados. Más allá de esto, también ellos fijaron la atención en los temas de la crisis y las soluciones posibles. También ellos se volverían hacia el artiguismo y sus fórmulas, buscando algún tipo de orientación. Ares Pons, Trías, Machado, Fernández Cabrelli, entre otros, se encuadraron más o menos ajustadamente en ese esquema.

34 Con todo, el Instituto de Profesores tiene hasta hoy un perfil casi específicamente docente; la formación como investigadores de sus egresados queda supeditada básicamente al esfuerzo personal de cada estudiante y al enfoque que cada docente imprima a su curso. Ateniéndonos al lapso 19511973, este Instituto contó (hasta ser arrasado por la dictadura) con una importante cantidad de docentes en Historia sumamente calificados, que acicateaban la vocación por la investigación.

35 Citado por Zubillaga, "Entre controversias...”, págs. 114-115. 
Resumiendo, la importante transformación que la historiografía uruguaya experimentó a lo largo del período que nos ocupa puede ser ubicada en la intersección de tres factores: a) la crisis económica y social, b) las modificaciones operadas en el sistema político — con el incremento del protagonismo de los sectores de izquierda-, y c) las mencionadas innovaciones registradas en el ambiente académico. En este rico contexto se afianzó el renovado interés por los estudios artiguistas. Por si fuera poco, se sumó un calendario de aniversarios relevantes, que bien podría ser considerado un cuarto componente de este esquema. ${ }^{36}$

\section{Resultados: enfoques ¿distintos? sobre asuntos de interés común}

Para el análisis de la forma y el espíritu con que se encaró el estudio del problema agrario en la Banda (luego Provincia) Oriental entre 1780 y 1820, se examinará la producción de algunas de las figuras más representativas, agrupándola cuando sea posible según criterios de pertenencia a determinada corriente historiográfica. No se pretende hacer aquí un abordaje minucioso, sino un relevamiento de los individuos, corrientes y títulos que puedan ser considerados como más representativos. ${ }^{37}$

Básicamente, tres núcleos temáticos serán tenidos en cuenta en este análisis: a) el problema del acceso a la tierra antes de la revolución y las relaciones sociales establecidas en ese marco; b) la producción material; y finalmente c) el artiguismo y la cuestión agraria (1811-1820), enfatizando en ese elemento esencial que fue el Reglamento de Tierras de 1815.

36 Sabido es que algunos momentos de recordación son siempre excelentes promotores de revisiones históricas. Entre 1950 y 1973, las conmemoraciones tuvieron una especial significación en Uruguay dada la expresividad numérica de aquellos aniversarios. En 1950, se cumplían cien años de la muerte de Artigas. Hubo además varios trascendentes "sesquicentenarios" (según se gustaba decir): en 1960, el del inicio de la revolución en el Plata con los hechos de Mayo; en 1961, el del comienzo de la insurrección en la Banda Oriental; en 1963, el del Congreso de Abril (de donde surgieron las llamadas "Instrucciones del XIII"); y en 1965 el de la aprobación del Reglamento de Tierras. En 1964 se celebró el cumpleaños número 200 del caudillo. Por último, en 1970 se conmemoró otro sesquicentenario muy poco festivo, el de la derrota del artiguismo.

37 Es necesario puntualizar, además, que existe una muy abundante y dispersa cantidad de artículos, de mayor o menor importancia, diseminados en numerosos diarios, semanarios, revistas no especializadas, boletines gremiales, etc. que, salvo casos excepcionales, no han sido tenidos en cuenta para la realización de este trabajo, basado fundamentalmente en la consulta de libros. El relevamiento de todo ese material desperdigado en publicaciones tan variadas es una tarea pendiente y a todas luces necesaria para el estudio en profundidad de esta temática. 


\section{1) La mirada de la "Nueva Historia"}

No sin ironía, Leticia Soler señala que Bases económicas de la revolución artiguista, de José Pedro Barrán y Benjamín Nahum, ${ }^{38}$ fue (visto que ambos se dedicaron luego a trabajar en otros núcleos temáticos) "el homenaje imprescindible que todos los historiadores uruguayos están obligados a hacerle al héroe". ${ }^{39}$ Publicado en 1964, tuvo casi de inmediato una segunda edición, y otra en 1968 (a la que siguieron numerosas reimpresiones) con importantes aditamentos en cuanto a la interpretación del Reglamento de Tierras, el origen del latifundio colonial y la agricultura en la revolución. Y aunque se trató (como muchos de los textos aquí mencionados) de un trabajo de síntesis, incorporó al análisis algunos elementos novedosos en el contexto historiográfico de entonces. Barrán y Nahum fueron dos de los principales exponentes de la llamada "Nueva Historia", corriente historiográfica nacida en los años 60 a impulsos fundamentalmente de la renovación generada en los precitados ámbitos académicos (Instituto de Profesores y, especialmente, Facultad de Humanidades y Ciencias). ${ }^{40}$

Fruto de una atención preferente a las nuevas corrientes (especialmente francesas), fue la preocupación por situar en primera línea algunos elementos materiales indispensables para un acercamiento correcto a la cuestión agraria: "factores [...] geográficos, demográficos, [...] comunicaciones y transportes", en clave regional y no estrictamente local, lo que le imprimió otro toque de originalidad al libro. ${ }^{41}$ Sobre un amplio escenario organizado en tres subregiones (litoral, serrana y patagónica), la "provincia-puerto" de Buenos Aires imponía su hegemonía sobre las provincias del

38 Egresados del Instituto de Profesores Artigas, ejercieron la docencia en Enseñanza Secundaria hasta ser destituidos por la dictadura. Ambos colaboraron con diversos medios de prensa; vale destacar la tarea de crítica historiográfica que Barrán realizó en el semanario Marcha en los años 60.

39 Soler, Leticia: La historiografía uruguaya contemporánea. Aproximación a su estudio, Montevideo, EBO, 1993, pág. 52. El interés posterior de estos historiadores los llevaría a temas como la historia rural de la segunda mitad del siglo XIX, y de allí al estudio del batllismo. En la actualidad trabajan separados; Barrán se dedica preferentemente a la historia cultural y de las mentalidades, y Nahum a la historia económica.

40 Para una caracterización de las corrientes historiográficas dominantes en el Uruguay de la segunda mitad del siglo XX, véanse Real de Azúa, Carlos: El Uruguay como reflexión [II], Capítulo Oriental, n. ${ }^{\circ}$ 7, Montevideo, Centro Editor de América Latina, 1969, págs. 582-591; Zubillaga, Carlos: "Historiografía y cambio social. El caso uruguayo", en Cuadernos del CLAEH, n. ${ }^{\circ}$ 24, octubre-diciembre/1982, págs. 35-37; Soler, La historiografía uruguaya..., págs. 29-98; Ribeiro, Ana: Historia e historiadores nacionales (1940-1990). Del ensayo sociológico a la historia de las mentalidades, Montevideo, Ediciones de la Plaza, págs. 40-64.

41 Barrán, José Pedro, y Nahum, Benjamín: Bases económicas de la revolución artiguista, Montevideo, EBO, 3. ${ }^{\text {a }}$ ed. (corregida y aumentada) 1968 (1. a ed. 1964), pág. 11. 
interior, mientras en la Banda Oriental se alzaba un firme competidor del poder porteño; la "lucha de puertos" estaba instalada. El análisis revela la fuerte impronta de investigadores como Miron Burgin y, fundamentalmente, Juan Pivel Devoto, de quien eran alumnos dilectos. ${ }^{42}$

El latifundio colonial había prosperado en la Banda Oriental gracias a la amplia disponibilidad de tierras y los costosos mecanismos de regularización de propiedades (que dejaban a los ricos en inmejorables condiciones ante los más pobres) y las mercedes reales, con el agregado de un fuerte ausentismo. Pese a conceder que existían ciertos rasgos de "feudalización" de la campaña (con su imagen de estancias convertidas en unidades autárquicas, "un fortín [con] su mesnada propia"), en los que el propio Pivel puso énfasis, estos autores destacaron que "eran una excepción dentro del panorama del latifundio 'ausentista' del período colonial". ${ }^{43}$ Otro rol desempeñaban los ocupantes precarios o medianos propietarios, naturalmente inclinados (y obligados) a permanecer en el campo, y en constante roce con los grandes estancieros. Con Pivel, Barrán y Nahum afirmaban que el famoso bando del gobernador Joaquín de Soria de agosto de 1810 (instando a los ocupantes precarios a regularizar su situación, a efectos de que el fisco recaudara lo necesario para enfrentar la revolución iniciada en Buenos Aires) tal vez "haya sido más efectivo en cuanto a provocar un espíritu revolucionario, que todas las encendidas proclamas [de] la Gaceta de Buenos Aires". ${ }^{44}$ Un enfoque historiográfico que tomara en cuenta, además, la cuestión fronteriza y su incidencia en la economía y la sociedad agrarias era imprescindible (aunque en este caso no se aventuraron mucho más allá del planteamiento del problema), y en ese sentido una adecuación a aquella realidad del concepto de frontera móvil, tan extendido entre los norteamericanos, les pareció totalmente pertinente. ${ }^{45}$

Sin embargo, cuestionaron el verdadero alcance del fenómeno del hambre de tierras, tantas veces invocado antes y después de publicado Bases económicas... Lo circunscribieron a la jurisdicción de Montevideo, descartándolo para el resto del territorio (dependiente de Buenos Aires y las Misiones Jesuíticas); "al Norte, el latifundio — que existía— no podía

42 Ciertos aspectos básicos del planteo piveliano de la historia uruguaya son recogidos (aunque matizados) por Barrán y Nahum. El de la independencia oriental como una suerte de "destino manifiesto" (apoyando el planteo en las tesis de Zorrilla de San Martín, nada menos) es uno de ellos Barrán y Nahum: Bases..., págs. 53-54.

43 Barrán y Nahum: Bases..., pág. 71.

44 Barrán y Nahum: Bases..., pág. 79.

45 Barrán y Nahum: Bases..., pág. 76. 
ocasionar los mismos traumas sociales que en el Sur". ${ }^{46}$ Pero aquí interesa destacar algo mucho más importante: el sentido de la crítica historiográfica, y también política, hecha por Barrán y Nahum al llegar a este punto. "El problema de la valoración del latifundio es mucho más complejo de lo que a primera vista parecería, [por lo que] toda vinculación del mismo con datos contemporáneos [...] resulta falsa y conlleva un error de óptica histórica. Si en la segunda mitad del siglo XX, una revolución rural inevitablemente pondría en discusión la utilidad social y económica del latifundio, en 1815, una revolución campesina como fue la de Artigas, no lo considerará como fenómeno madre de los restantes, sino simplemente como un síntoma de una realidad más variada y más rica" ${ }^{47}$ La decidida promoción de la reforma agraria que la izquierda haría antes de 1973, implicó un realce de visiones históricas que tuvieron muy poco en cuenta una advertencia tan relevante.

En cuanto a la producción material, algunos asertos tradicionales sobre sus características no fueron radicalmente cuestionados en esta obra: la casi absoluta preeminencia de una economía de ganadería extensiva, con un ínfimo desarrollo de la agricultura, y ésta circunscripta como elemento relevante al espacio inmediatamente adyacente a Montevideo, son los aspectos más salientes del análisis. Los diagnósticos "pesimistas" respecto de las posibilidades de la agricultura colonial parecen provenir de algunas certezas bastante generalizadas en la historiografía uruguaya que, grosso modo, pueden resumirse de esta manera: a) existía un débil mercado interno, que resultaba ser factor insuficiente para la agricultura, rubro que, por lo demás, tenía clausurado el horizonte exportador en tanto éste era monopolizado por los derivados de la ganadería; o bien b) la existencia efectiva de mercados consumidores (inclusive externos) no alcanzaba a mitigar los efectos contraproducentes de una estructura económico-política montada en beneficio, a fin de cuentas, de la ganadería. Hasta no hace mucho tiempo, un enfoque de estas características parecía ya "cosa juzgada". Sin embargo, es posible introducir, cuidadosamente, algunas variantes.

Evidentemente, en muy buena medida la economía agraria entre finales del siglo XVIII y (por lo menos) los comienzos del XIX era fundamentalmente pecuaria, y por ello puede darse por descartada la viabilidad de una crítica radical a la "tesis ganadera". Con todo, las investigaciones más recientes han demostrado que la campaña rioplatense colonial estaba menos

46 Barrán y Nahum: Bases..., pág. 77.

47 Barrán y Nahum: Bases... 
uniformemente dominada por un personaje (el gaucho) y una forma de economía (la ganadería extensiva) de lo que hasta no mucho tiempo atrás se creía. La Banda Oriental, al menos en sus zonas sur y sur-oeste, no estuvo ajena a esa infravalorada diversidad material (que fue también social). ${ }^{48}$

En Barrán y Nahum encontramos un clara sintonía con la postura según la cual resultaba imposible vencer los obstáculos del sistema productivo, más allá de que el circuito comercial estuviese abierto a la producción agrícola. "Se ha señalado a menudo [dicen analizando el contexto regional] la existencia de un factor que conspiraba contra el desarrollo agrícola: la falta de mercados." Luego de recordar (citando a Manfred Kossok), ${ }^{49}$ que el cabildo porteño buscó por todos los medios impedir que la producción triguera se volcase al mercado dejando así desprovista de pan a la población de la ciudad, agregaban que "sin el aliciente de la exportación y con un control oficial de los precios, los estímulos posibles para desarrollar la agricultura, desaparecían. Pues bien, esto, que es indudable en el caso bonaerense, adquirió otros tonos e importantes variantes en la Banda Oriental". ${ }^{50}$

Aunque hoy sabemos que la agricultura bonaerense fue bastante más dinámica que lo que esta visión sugería, encontraron fuertes líneas de semejanza entre las prácticas agrícolas de ambas riberas del Plata. Similitudes especialmente notables percibieron entre los problemas que debían enfrentar quienes se dedicaban a cultivar la tierra: los dictados de un poder político aliado con los grandes ganaderos ${ }^{51}$ escasez de mano de obra,

48 Nuevos enfoques al respecto han sido aportados por la reciente historiografía argentina. Véase Gelman, Jorge: "Producción campesina y estancias en el Río de la Plata colonial. La región de Colonia a fines del siglo XVIII", en Boletín del Instituto de Historia Argentina y Americana

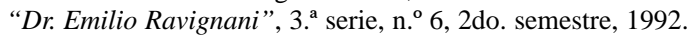

49 En El Virreinato del Río de la Plata (obra influyente en la historiografía rioplatense, publicada por primera vez en español por la editorial Futuro, de Buenos Aires, en 1959 y reeditada por La Pléyade en 1972), Kossok llegó a la conclusión de que en el enfrentamiento entre agricultura y ganadería, aquella resultó "estrangulada” por su rival. Consideró además que el modelo económico-social colonial segó "toda posibilidad de que la agricultura alcanzara un desarrollo que rebasara las exigencias inmediatas de [un] mercado local" de escasa relevancia para este autor. Kossok, Manfred El Virreinato del Río de la Plata. Su estructura económica-social [sic], Buenos Aires, La Pléyade, 1972, págs. 94-95.

50 Barrán y Nahum: Bases..., págs. 137-138.

51 "Es [...] la lucha del fuerte (el gran ganadero respaldado por la autoridad colonial) y el débil (el agricultor con escaso terreno)" (Barrán y Nahum: Bases..., pág. 141). Esta formulación es tributaria de las visiones más tradicionales de la campaña porteña. La reciente producción historiográfica, sin ser monolíticamente discorde con ella, nos pone ante una realidad muy distinta y más rica en matices: la dicotomía "gran latifundio ganadero" versus "pequeño agricultor indefenso" parece más propia del período posindependentista que del colonial. En tal sentido, consúltese Garavaglia, Juan Carlos: "Un siglo de estancias en la campaña de Buenos Aires: 1751 a 1853", en Hispanic American Historical Review, 79:4, noviembre/1999; en págs. 715-722 de este artículo se explora el vínculo entre estancias, ganadería y agricultura en dicho lapso. 
y limitaciones derivadas del régimen de minifundio, este sí, un verdadero problema de larga duración. Dicho aspecto de la cuestión agraria dieciochesca mantenía para Barrán y Nahum plena vigencia en 1963, en contraposición a lo acontecido con ciertas malas lecturas del problema del latifundio, muy cuestionadas, según se ha visto ya: "toda la documentación y los autores estudiados nos permiten afirmar que lo anterior no es una extrapolación de una problemática contemporánea, sino una realidad tremenda que se arrastra en el país desde el período colonial." ${ }^{2}$

Llegada la instancia revolucionaria, la cuestión agraria ocupó el centro de la escena, especialmente en la Banda Oriental, donde el foco principal de agitación no se instaló en la ciudad-puerto, como sí lo hizo en la sede del poder virreinal. Montevideo fue, más bien, el enemigo a vencer. ${ }^{53}$

Para estos dos historiadores, el elemento de diferenciación de la revolución oriental en el contexto americano fue precisamente su carácter agrarista, lo que significó tanto una participación efectiva del "campesinado" (concepto que aquí no aparece desarrollado) como determinadas características del programa social del artiguismo. Les interesaba dejar bien delimitada la diferencia entre una mera "guerra de independencia" y lo que para ellos efectivamente constituyó aquel proceso, una revolución social. Iniciado el conflicto, la tradicional falta de seguridad en la campaña (ejemplificada en la proliferación de contrabandistas, salteadores, incursiones indígenas, precariedad de los asentamientos humanos, etc.) se vio agravada por la insurrección y la llegada de las tropas portuguesas.

Ante ese estado de cosas, el artiguismo se propuso al mismo tiempo pacificar la campaña, promover la producción y fomentar el asentamiento de poblaciones, mediante una política de reparto de tierras que era vista como la continuación de una labor emprendida en 1800 junto a Félix de Azara, en el norte del territorio oriental, y proseguida con algunos repartimientos posteriores a 1811. "Todos estos antecedentes est[aba]n demostrando una perfecta continuidad en su faz de caudillo campesino y distribuidor de tierras". Se nos presentaba entonces un Artigas que ya antes de

52 Barrán y Nahum: Bases..., pág. 143.

53 En un artículo breve pero sugerente (que incursiona además en un campo que la historiografía uruguaya elude con demasiada frecuencia: el de la historia comparada), Carlos Mayo ha señalado que las sustanciales diferencias entre formas de apropiación y tamaño de las estancias en la Banda Oriental y la campaña bonaerense, constituyen una de las claves de diferenciación entre ambos procesos revolucionarios. Véase Mayo, Carlos: "Estructura agraria, revolución de independencia y caudillismo en el Río de la Plata, 1750-1820 (algunas reflexiones preliminares)", en Anuario IEHS, n. ${ }^{\circ}$ 12, Tandil, 1997. 
1815 era, de algún modo, naturalmente reformador: "Esta política, intuitiva en el fondo, se har[ía] plenamente consciente y alcanzar[ía] una rica formulación ideológica con el Reglamento Provisorio, manifestación ahora de un conductor de pueblos y no de un oficial subalterno del Estado español". ${ }^{54}$

Según esta perspectiva, el Reglamento de 1815 (más precisamente, "Reglamento Provisorio de la Provincia Oriental para el Fomento de su Campaña y Seguridad de sus Hacendados"), abrevando en la tradición de algunos planes reformistas borbónicos, daba a la tenencia de la tierra un carácter "civilizador" (fijando poblaciones con un criterio productivo, y fortaleciendo la presencia humana en esa porosa frontera entre el territorio oriental y los dominios portugueses). Adoptaba además un giro enteramente original por cuanto "el derecho de propiedad aparecía vinculado a la justicia revolucionaria, era un premio dado a los valerosos gauchos, indios y mestizos, que habían expuesto sus vidas y haciendas en la lucha". ${ }^{55} \mathrm{Se}$ admitía que algunas disposiciones del Reglamento, como la obligatoriedad para los peones de portar papeleta de conchabo so pena de reclusión, significó "una concesión [de quien] integraba sus milicias precisamente con los 'gauchos vagos' [...], a los hacendados". ${ }^{56}$

Además de destacar el carácter revolucionario de esta medida, Barrán y Nahum discutieron la afirmación tradicional (en este caso, en versión de Isidoro de María) de que la aplicación del Reglamento tuvo ciertamente resultados modestos. En torno a este nudo temático (los reales alcances del proyecto agrarista de 1815 y la evaluación que del mismo podía hacerse) se desarrolló una buena parte de la discusión entre esta nueva historiografía de izquierda y las versiones "celestes" del artiguismo, más proclives a destacar el costado cívico del movimiento. Basándose en la documentación existente, se concluía en Bases... que aquellas disposiciones se aplicaron "con eficacia [...] en lo que significa confiscación de las propiedades enemigas [esto es, las de "malos europeos y peores americanos"] con auténtico afán revolucionario". ${ }^{57}$ Una prueba contundente de ello estaba dada por la virulencia con que las clases altas, muy poco después, juzgarían el proyecto artiguista. ${ }^{58}$ Sin embargo, nuevamente hubo espacio para algunas restas:

54 Barrán y Nahum: Bases..., pág. 108.

55 Barrán y Nahum: Bases..., pág. 117.

56 Barrán y Nahum: Bases..., pág. 119.

57 Barrán y Nahum: Bases..., pág. 121.

58 Sobre el éxito alcanzado en la aplicación del Reglamento, véase un enfoque discrepante y más reciente en Vazquez Franco: Tierra y Derecho..., en especial págs. 171-181. 
más allá de juzgar fruto del "temor de las clases altas" la crítica al Reglamento emprendida por Dámaso Larrañaga en 1816, estos autores admitían que el proyecto mostraba flaquezas. Una de ellas, el no impedir puntualmente la subdivisión de las propiedades entre los herederos (lo que "provocaría, a la larga, minifundios improductivos"). ${ }^{59}$ Otra, aunque menos evidente, la falta de atención prestada por Artigas a la agricultura. El caudillo expresó en 1815, en una comunicación al Cabildo de Guadalupe (Canelones), que "emprenderlo todo en estos momentos [o sea, destinar esfuerzos a fomentar ganadería y agricultura a la vez] ser[ía] no abarcar nada". En otras propuestas se afirmaría (se verá luego) que en esto había simplemente un respeto de Artigas por el deseo de los beneficiarios, o una muestra de sus dotes de estratega. Pero Barrán y Nahum avanzaron en otra dirección, haciendo una evaluación más "política" del contexto. Se trataba para ellos del "temor del caudillo a enemistarse una vez más con los grandes estancieros". 60

El Reglamento, en suma, constituyó desde esta óptica un documento político de amplios alcances en el desarrollo económico y la justicia social. Aunque destinado a favorecer también a los hacendados, éstos mantuvieron con su impulsor una relación "ambivalente", puesto que al mismo tiempo que se hablaba de garantizar su seguridad, se ponía en duda el derecho de propiedad. Como intento de "encauzar la espontaneidad revolucionaria [encarnada en el gaucho] que no tenía objetivos políticos definidos y sólo se expresaba por medio del saqueo y el pillaje", Artigas logró su objetivo; los sectores más bajos de la sociedad rural captaron su mensaje, por lo menos "de una manera primitiva y difusa". Para Barrán y Nahum (mucho menos interesados que otros en distinguir entre un gauchaje improductivo y un paisanaje formado en los hábitos de trabajo) el gaucho "no [...] abandonó [al caudillo]. Fueron otros". ${ }^{61}$

Una aproximación diferente y más tangencial al tema, fue practicada por quien entonces era un joven integrante de esta nueva camada de historiadores: Carlos Zubillaga. ${ }^{62}$ En el marco de los múltiples eventos de cele-

59 Barrán y Nahum: Bases..., pág. 122.

60 Barrán y Nahum: Bases..., pág. 155.

61 Barrán y Nahum: Bases..., pág. 131.

62 Licenciado en Historia por la Facultad de Humanidades y Ciencias, antes de iniciarse la dictadura se desempeñó como docente en esta institución durante un breve período y en el Instituto de Profesores Artigas, hasta ser destituído. Desarrolló una fuerte militancia estudiantil y sindical (en el gremio bancario), y en el Partido Demócrata Cristiano, una de las fuerzas fundadoras del Frente Amplio. 
bración llevados a cabo en 1964 (bicentenario del nacimiento de Artigas), el Comité Central Israelita del Uruguay convocó a un concurso literario sobre el tema "Artigas y los Derechos Humanos". Zubillaga resultó ganador, con una obra que se publicó precisamente con ese título. ${ }^{63}$

En este libro, Zubillaga partió de la conceptualización de los derechos humanos y el esbozo de algunas líneas de su evolución histórica a través de distintos países del mundo occidental, para luego abordar el estudio de esta temática en el proceso revolucionario iniciado en 1811. Identificó nueve derechos, enunciados explícitamente en documentos del artiguismo o reflejados en materiales de diversa índole. En tres de los apartados diagramados por el autor (el principio de igualdad, la libertad de trabajo y el derecho de propiedad) se encuentran vinculaciones directas entre derechos humanos y cuestión agraria. En esta obra de juventud, Zubillaga parece haberse dejado llevar por aquel clima de "artiguismo ambiente", rozando por momentos el discurso apologético (tentación que habría de eludir cuidadosamente en toda su obra posterior) ${ }^{64}$

En lo relativo a los nexos entre cuestión agraria e igualdad, el punto crucial fue fundamentalmente el problema indígena. En comparación con Bolívar (que reconocía al indígena sus derechos, pero lo veía como un escollo para el triunfo criollo en la revolución), señaló Zubillaga que "la prosa artiguista pon[ía] de relieve la identificación de Artigas con el indio", en tanto el caudillo afirmó que los nativos tenían "el principal derecho" a alcanzar la felicidad, por lo cual el Reglamento del 15 los tendría como beneficiarios. ${ }^{65}$

También las preocupaciones agraristas y derecho de libertad de trabajo se daban la mano en este Reglamento. El artiguismo, apuntó Zubillaga, buscaba generar condiciones para la expansión de hábitos productivos, estando reservada a quienes trabajasen la posibilidad de acceder a beneficios económicos. La interpretación del concepto de "que los más infelices serán los más privilegiados" era algo distinta; "la concepción del trabajo-

63 Zubillaga, Carlos: Artigas y los Derechos Humanos, Montevideo, Comité Central Israelita del Uruguay, 1966.

64 Existe además una semejanza importante entre Zubillaga y Barrán y Nahum: su producción historiográfica posterior estaría casi enteramente centrada en el estudio de otros asuntos (inmigración, movimiento obrero, historiografía, historia política uruguaya del siglo XX).

65 Zubillaga: Artigas..., págs.80-81. Citó en tal sentido el muy elogioso oficio de Artigas a Andrés Artigas ("Andresito"), gobernador de Misiones, en el que llamaba a los nativos a "destrui[r] la tiranía y gusta[r] el deleitable néctar que os ofrecen con las venas del corazón que lo traigo deshecho por vuestro amor", pág. 81. 
función social ju[gó] a manera de nivelador, reparando las desigualdades económicas a la vez que cumpliendo con el deber del Estado de asegurar un medio de vida al 'proletariado campesino de la época' (según la feliz expresión de Edmundo Narancio $\left.{ }^{66}\right)$ ".

La idea de un derecho de propiedad garantizado en función de las posturas que cada individuo adoptara ante el hecho revolucionario, trasuntaba para Zubillaga una actitud bastante alejada de un liberalismo clásico como el que los forjadores de la encrática "leyenda celeste" podían adjudicarle al caudillo de 1811. Aquí, se estaba "no [ante] una concepción individualista y liberal de que cada hombre pueda realizar el trabajo que crea conveniente, sino que el trabajo - fuente de creación del standard vital de la comunidad - deb[ía] ser regulado por el Estado en consideración de la misma sociedad".

¿Qué determinaba todo esto? Que los conceptos de "familia, igualdad económica, destrucción de privilegios" ocuparan el centro de la escena, en 1815 como en 1966, "cargados de sentido social, que si aún hoy no logran [...] su consagración definitiva" su sola enunciación venía a confirmar "la perdurabilidad del ideario artiguista, a través de concepciones fermentales, producto de la genialidad creadora del Prócer". ${ }^{67}$

Y en relación, precisamente, al derecho de propiedad, el documento de setiembre de 1815 fue "el cuerpo jurídico de mayor importancia". Nuevamente destacó el "carácter nivelador de las desigualdades económico-sociales" del Reglamento, desde que estaba animado por la doctrina de la "función social de la propiedad" en tanto se la aceptaba y estimulaba pero sin permitir que la misma "vulnera[ra] los derechos de la sociedad". Esto implicaba una "sanción al latifundio" ${ }^{68}$ ¿A todos los latifundios del territorio oriental? No avanzó en mayores precisiones al respecto; anotó, sí, que la reforma se fundaba en "un criterio que t[enía] base política y t[endía]

66 Edmundo Narancio fue una figura relevante en la historiografía uruguaya del siglo XX. Aunque no puede ser considerado un hombre de izquierda (era ciertamente un liberal), sus concepciones sobre el artiguismo (que a su vez eran tributarias, según propia confesión, de las de Eugenio Petit Muñoz) alcanzaron mucha difusión, y el trabajo de Zubillaga que aquí se cita no fue el único en tenerlo como referencia. Primer director del Instituto de Investigaciones Históricas de la Facultad de Humanidades, dejó el cargo al perder el concurso para su provisión en efectividad (concurso que ganó Petit, en 1962). Su actitud hacia la Facultad y la Universidad en general sería cada vez más crítica hacia finales de la década de 1960, y apoyó decididamente la intervención de 1973 (siendo nombrado rector por el gobierno dictatorial del que fue también ministro de Educación y Cultura). Para una síntesis de su pensamiento sobre el artiguismo en 1950, véase "El Reglamento de 1815", en Narancio, Edmundo (dir.): Artigas, Montevideo, Ediciones de "El País", 1950.

67 Zubillaga: Artigas..., págs. 101-102.

68 Zubillaga: Artigas..., págs. 114-115. 
al afianzamiento de la Revolución", aunque de inmediato agregó que no se trataba "solamente [de] un fin político, sino [también de] un fin social" el que perseguía "el Estado" con estas disposiciones. ${ }^{69}$ Pero no analizó específicamente la vinculación entre el Reglamento y el doble objetivo político de asegurar el respaldo de "los más infelices" y el de los hacendados afines a la revolución. Más bien se interesó en subrayar los nexos entre "los conceptos de trabajo-función social y propiedad-función social, siendo el primero sustento del segundo y teniendo ambos vigencia en tanto que la caracterización 'social' e[ra] el elemento determinante de su consagración práctica". ${ }^{70}$

Desde una óptica diferente como la de los derechos humanos, Zubillaga (sin llegar a afirmar, como lo haría el revisionismo, que el artiguismo era lisa y llanamente "un programa" para la vida política de los años 60) también destacaba al cierre de su estudio la vigencia de las concepciones artiguistas - incluyendo las agrarias-, en las que podía reconocerse "aún hoy, rasgos sorprendentes de modernidad [eficaces como] acicate para las reformas enunciadas en los años de la Patria Vieja y todavía preteridas". ${ }^{71}$

\section{2) Izquierda y revisionismo histórico}

La historiografía uruguaya conoció varios casos de "revisionismo de izquierda"; autores muy conocidos y libros de gran difusión, casi por entero vaciados en el molde de la ensayística, que analizaron los temas del coloniaje y la revolución y se publicaron a lo largo del período que nos ocupa. ${ }^{72}$ Washington Reyes Abadie, Oscar Bruschera y Tabaré Melogno integraron uno de los más notorios equipos de historiadores de este período, y que mejor representó los principios de la historiografía revisionista. ${ }^{73}$ Casi

69 Zubillaga: Artigas..., pág. 117.

70 Zubillaga: Artigas..., pág. 119.

71 Zubillaga: Artigas..., pág. 127.

72 Real de Azúa: El Uruguay como reflexión (II)..., págs. 582-586; Zubillaga: "Historiografía y cambio social...”, págs. 36-37; Soler, La historiografía uruguaya..., págs. 29-39; Ribeiro: Historia $e$ historiadores..., págs. 40-49.

73 La ubicación de este terceto en el campo de la historiografía de izquierda es algo que requiere algunas precisiones. El itinerario ideológico de Reyes Abadie, sin duda la personalidad más descollante del equipo, fue hasta su reciente fallecimiento un tanto errático. Durante buena parte de su vida fue un simpatizante más o menos inorgánico del Partido Nacional, aunque también integró el círculo de intelectuales que se adhirió al ya mencionado "ruralismo" de Benito Nardone, en los inicios de este 
toda su obra giró en torno al tema del artiguismo, sin descuidar los años previos; su interpretación en clave tridimensional del período colonial (esbozada en anteriores trabajos y que diera título a uno de sus principales libros, La Banda Oriental: pradera-frontera-puerto) haría un largo camino en nuestra historiografía. ${ }^{74}$ Luego de establecer los fundamentos básicos de dicha trivalencia, analizaron la "fisonomía de la pradera". Sintetizaban entonces varios de los supuestos más transitados de la historiografía revisionista: la economía ganadera como única capaz de imprimir su sello a la vida rural (utilizan el concepto de "Edad del cuero"), la faena campera como elemento capaz de transformar al gaucho en paisano, o individuo económicamente productivo; y culminaban con una caracterización de la estancia que aproximó el planteo a la teoría piveliana de la "feudalización". Obsérvese el vocabulario empleado: "la estancia [fue] un centro económico-social de vida autárquica, donde se ofrec[ía] la posibilidad de trabajo; [fue] un lugar de refugio [...] donde se guarda[ba]n armas y p[odía] organizarse una hueste para la guerra. [...] Ella form[ó], junto con las capillas y las pulperías desperdigadas por la semidesértica área rural, los centros básicos de la sociabilidad campesina". ${ }^{75}$

Las tres formas básicas de explotación de la riqueza ganadera (el latifundio de ganadería cimarrona y propietario ausentista; la pequeña y mediana extensión en manos de propietarios u —en la mayor parte de los casos- ocupantes precarios; las faenas clandestinas en manos de gauchos, herederos de las prácticas de las vaquerías), articuladas con el permanente contrabando, dieron el tono a la vida rural colonial. La vida en la pradera se desarrolló así como un permanente contrapunteo entre los intereses de sus habitantes, y los de la ciudad portuaria y los poderes imperiales asomados a la frontera. La dicotomía campo-ciudad, tan cara al revisionismo,

movimiento (junto a Real de Azúa, Alberto Methol Ferré, José Claudio Williman, etc.). En determinados momentos insinuó un apoyo al Frente Amplio, partido al que sí adhirió muy formalmente Oscar Bruschera, firmante en octubre de 1970 (junto a muchos otros individuos, entre los que estaban historiadores como Germán D’Elía y Eugenio Petit Muñoz), del llamado público a constituir una alianza de grupos de izquierda. Bruschera fue además diputado por esta fuerza política entre 1972 y 1973. Melogno mantuvo siempre un perfil mucho más bajo en todos los planos. Ejercieron la docencia en Enseñanza Secundaria y también la labor periodística, especialmente Bruschera, director del diario Ahora hasta su clausura por la dictadura en 1973. Si se comparan las tesis de todo el equipo con las que sostiene Bruschera en un estudio individual (Artigas, de 1969) coinciden en todo lo importante; incluso en su redacción guardan semejanzas. Con esta salvedades, es admisible que su producción sea valorada como una mirada "de izquierda" sobre los temas abordados.

74 Reyes Abadie, Washington; Bruschera, Óscar, y Melogno, Tabaré: La Banda Oriental: pradera-frontera-puerto, Montevideo, EBO, 1966.

75 Reyes Abadie, Bruschera y Melogno: La Banda Oriental..., pág. 51. 
postuló aquí la existencia de un medio agrario reducto de las virtudes libertarias: "La ciudad murada, con su autoridad y su afán de lucro, le aparecerá [al hombre de la pradera: gaucho, paisano, indígena, etc.] como la sede de la prepotencia y de la avaricia, el bastión del despotismo 'chapetón'. [...] El hombre de la pradera [...] refiere a su 'pago' y a su tierra su definición de 'americano' y su vocación de libertad". ${ }^{76}$

Si todas las formas de ocupación de tierras y las relaciones sociales nacidas en sus marcos estaban condicionadas por esa triple condición de territorio ganadero, fronterizo y portuario que la Banda Oriental tenía, era la frontera lo que asomaba como elemento principal. La Banda Oriental... exhibe, como rasgo característico de toda la obra del equipo, un definido interés por el recorte regional, y no meramente local, del objeto de estudio. La cuestión agraria aparece en esta óptica íntimamente ligada al papel geopolítico que la Banda Oriental desempeñaba en el tránsito del siglo XVIII al XIX. La frontera era, pues, "la condicionante decisiva en la conformación de los estilos y formas de vida que otorgan fisonomía dual y hasta antagónica al proceso histórico de la Banda Oriental". ${ }^{77}$

En lo tocante a la relación entre ganadería y agricultura, la interpretación hecha por Barrán y Nahum (tributaria a su vez, según va dicho, de las investigaciones de Kossok) sería in extenso suscripta por Reyes Abadie, Bruschera y Melogno. En este caso, sin embargo, la tendencia a situar las actividades agrícolas como verdadero "arte menor" se veía reforzada. Los dos capítulos de La Banda Oriental..., dedicados específicamente al estudio de la estructura agraria (el quinto, "La fisonomía de la pradera", y el sexto, "El arreglo de los campos"), ocupan 45 páginas, pero sólo en las dos finales existen referencias a la agricultura. ${ }^{78}$

En la segunda mitad de la década de 1960 estos autores publicarían una de las obras más importantes sobre el artiguismo aparecidas en nuestro país: El ciclo artiguista. ${ }^{79}$ En realidad, los temas que abordaron en este extenso escrito habían sido tocados ya en algunas publicaciones muy anteriores, ${ }^{80}$ en las que recopilaban el resultado de una extensa labor de docen-

76 Reyes Abadie, Bruschera y Melogno: La Banda Oriental..., pág. 121.

77 Reyes Abadie, Bruschera y Melogno: La Banda Oriental..., pág. 119.

78 Reyes Abadie, Bruschera y Melogno: La Banda Oriental..., págs. 91-92.

79 Reyes Abadie, Washington; Bruschera, Óscar, y Melogno, Tabaré: El ciclo Artiguista, Montevideo, Departamento de Publicaciones de la Universidad de la República, 1968. Para la realización de este trabajo se consultó la quinta edición (Margarita Silberberg-Impresora Cordón, 1978).

80 Reyes Abadie, Washington: Bruschera, Óscar, y Melogno, Tabaré: El ciclo Artiguista, Curso de Historia Nacional (3 tomos), Montevideo, Medina (mimeo), 1948, y Documentos de Historia Nacional. El ciclo artiguista, Montevideo, Medina, 1950. 
cia en historia uruguaya y americana. Siempre en el terreno del ensayo, El ciclo..., ofrecería una síntesis de la —a esa altura - ya muy numerosa (y en gran medida, apologética) bibliografía sobre el artiguismo, con el aditivo de una copiosa batería de documentos editados (habían aparecido ya 8 tomos del Archivo Artigas). ${ }^{81}$ Constituyó sin duda una de las visiones más abarcadoras (y más difundidas) ${ }^{82}$ del artiguismo desde los puntos de vista político, social, económico y militar, enfatizando fuertemente en su carácter revolucionario, popular y americanista. Facetas todas que era necesario rescatar contra su omisión sistemática (e interesada) por parte de la historiografía oficial.

Veamos qué tratamiento recibió en este trabajo el proyecto agrario del artiguismo. Para comenzar, una delimitación de los espacios: el campo se enfrentaba a la ciudad. Mucho se ha dicho ya sobre la tendencia revisionista a la exacerbación de este conflicto ${ }^{83}$ sin embargo, debe decirse que las propias características del proceso revolucionario oriental (por lo menos entre 1811 y 1814) proporcionaron insumos para análisis de este corte. ${ }^{84}$ Con todo, la tendencia a la esquematización no faltó a la cita. Así, partiendo de una identificación de "los dos ámbitos que polarizaban la vida histórica de la Banda: la ciudad-puerto y la pradera", ${ }^{85}$ dentro de los muros de la primera quedaban encerrados todos los elementos aliados al statu quo colonial, mientras que en la campaña tuvo lugar "la señal de la insurrección general" ${ }^{86}$ Esa campaña fue el ámbito donde surgió ese gran frente policlasista, compuesto inicialmente por "hacendados criollos [...] promotores de la revolución" y por los paisanos de todos los pagos, acaudillados por Artigas. Se configuró así un fuerte movimiento agrarista, cohesionado por la figura del caudillo e integrado por " "naturales' de 'vincha' y alarido [...], 'gauchos' y 'changadores' [...] escuadrones de indios tapes [...], las familias de criollos pobres, hacendados rústicos, [sin que faltaran] algunos patricios de renombre, de altiva prosapia y hacienda caudalosa [...], curas patriotas, de evangelio breve y sermón rusoniano [sic]", etc. ${ }^{87}$ La entona-

81 A lo cual debe sumarse una gran cantidad de otras recopilaciones (véase el apartado "Fuentes documentales" de la bibliografía de El ciclo..., págs. 505-508).

82 La obra tuvo seis ediciones hasta 1986, todo un éxito en el Uruguay.

83 Acerca de los diversos niveles de motivaciones que frecuentemente animaron, más o menos explícitamente, los análisis de corte revisionista, es indispensable la consulta de los excelentes párrafos que al tema ha dedicado Real de Azúa, en El Uruguay como reflexión (II), págs. 582-586.

84 Mayo: "Estructura agraria...".

85 Reyes Abadie, Bruschera y Melogno: El ciclo..., tomo 1, parte 2, pág. 57.

86 Reyes Abadie, Bruschera y Melogno: El ciclo..., pág. 58.

87 Reyes Abadie, Bruschera y Melogno: El ciclo..., pág. 59. 
ción romántica de esta descripción (muy típica de Reyes Abadie, por otra parte), se extiende a la propia valoración del medio físico en el que el artiguismo cobró vida; en este caso se echó mano a la prosopopeya: "los horizontes de la tierra, expresión y dimensión de una patria que presiente la formidable visión del Jefe oriental — geopolítico por ‘baquiano’ y rumbeador-[...]". ${ }^{88}$

Analizado el escenario, ingresaron al estudio extenso del programa propiamente agrario del artiguismo. Para ello, siguieron la secuencia descripción comentada-análisis de objetivos-aplicación-valoración. Subrayaron el carácter integral del programa agrario, cristalizado en el Reglamento de Tierras de 1815, que recogiendo elementos de la tradición antilatifundista del derecho indiano y de los programas de "arreglo de los campos" venía a solucionar múltiples problemas: productivos (aumento de la producción y de la productividad), sociales (combatiendo la pobreza, la delincuencia y la migración rural, haciendo hincapié en el hecho de que "los más infelices ser[í]an los más privilegiados", una "idea rectora" de todo el programa), ${ }^{89}$ geopolíticos (estimulando la fundación de pueblos, ocupando el territorio y fortaleciendo la frontera) y jurídicos. A la hora de exponer los objetivos del Reglamento de 1815, los autores no ocultaron su entusiasmo: "se aspiraba a la reparación y la justicia [para el beneficiario], el término de su marginalización; su ascenso social a una clase de medianos propietarios. [...] No era la gracia, sino la justicia; no era la prebenda, sino la oportunidad; no era la facilidad, sino el esfuerzo". ${ }^{90}$

La aplicación del Reglamento enfrentó problemas; pero en el balance resultó exitosa, y para demostrarlo recurrieron a referencias numerosas que venían a refrendar la veracidad de aquel aserto. Los estudios de Agustín Beraza, Ariosto Fernández, Flavio García, Huáscar Parallada, Lucía Sala y su equipo, fueron extensamente citados como elementos probatorios de la efectiva puesta en práctica del proyecto de $1815 .{ }^{91}$ Consecuentemente, se tiende a calificar de incorrecto cualquier atisbo de crítica, o de simple identificación de una carencia, en determinados aspectos de este programa

88 Reyes Abadie, Bruschera y Melogno. Subrayado mío.

89 Reyes Abadie, Bruschera y Melogno: El ciclo..., tomo 2, pág. 264.

90 Reyes Abadie, Bruschera y Melogno: El ciclo..., pág. 278.

91 Relata refero ("como lo cuentan, lo cuento") dice la expresión latina. Real de Azúa advirtió contra los peligros de unas prácticas historiográficas (habituales entre muchos revisionistas) en las que campeaba "el predeterminado esquema demostrativo, l'histoire à thèse, que sólo emplea lo que pueda ratificarlo, y excluye, o tergiversa, o ignora, cualquier tipo de dato cuyo significado pudiera amenazarlo”. Real de Azúa: El Uruguay como reflexión (II)..., pág. 583. Similares consideraciones en Zubillaga, "Historiografía y cambio...", págs. 36-37. 
agrario. Por ejemplo, se nos decía que "yerran quienes [...] piensan que Artigas debió efectuar una 'concesión' a los grandes propietarios" cuando fijó reglas claras contra la marginalización y la delincuencia. ${ }^{92} \mathrm{O}$ bien, a quienes sostenían que el descuido por la agricultura era otro caso de concesión a los hacendados — hipótesis propuesta por Barrán y Nahum—, se les respondió que dicha postergación se encuadraba dentro de un plan político ajustado como un mecanismo de relojería: "Artigas sistematiza[ba] y diagrama[ba] con previsión de estadista, el itinerario de las obras posibles de realizar". ${ }^{93}$ La evaluación final, pues, no podía ser sino ampliamente laudatoria: "vemos cuán hondo caló en la realidad social de su tiempo, cuán ambicioso y realista fue en sus objetivos [ese programa agrario impulsor de la] exaltación de aquellos 'infelices' que habrían de ser los más privilegiados, o sea los más atendidos [...]". ${ }^{94}$

Para otro exponente del revisionismo de izquierda, Roberto Ares Pons ${ }^{95}$ la caracterización de la Banda Oriental como "pradera, frontera y puerto" era entonces la que mejor permitía captar las precondiciones de la revolución. En un trabajo publicado por primera vez en Buenos Aires en 1961, puso énfasis en dos elementos. Uno de ellos, la recurrida dialéctica Montevideo-campaña. La ciudad era, en cualquier caso, "el representante de un Poder foráneo, impon[iendo] leyes que se funda[ba]n en ajenos intereses [...]". En cambio en la campaña ganadera, asfixiada por la mezquina ciudad portuaria "se [ib]a dibujando la fisonomía criolla, los gérmenes de la nacionalidad" ${ }^{96}$ Como segundo polo de atracción aparecía el gaucho, no ya como un tipo humano específico del mundo colonial (y eventualmente inserto en la economía como trabajador zafral) sino como un precursor del ser nacional irredento. Aunque lo consideró "un tipo histórico no viable, que debía perecer como estamento social para que la nación fuese posible" (es imposible no pensar en el concepto mitrista de la historia al leer estas líneas de Ares), el gaucho era portador de "los rasgos específicos de la nacionalidad", cuyos "hábitos y tendencias se conviert[ía]n en patrimonio de toda la masa rural y, por ende, del pueblo oriental en lo que tiene de peculiar y distintivo en el concierto de las colectividades huma-

92 Reyes Abadie, Bruschera y Melogno: El ciclo..., tomo 2, pág. 278.

93 Reyes Abadie, Bruschera y Melogno: El ciclo..., pág. 300.

94 Reyes Abadie, Bruschera y Melogno: El ciclo..., pág. 306.

95 Docente, dirigente sindical y militante político, fundó la agrupación de izquierda Nuevas Bases en la década de 1960. En la segunda mitad de la de 1950 editó la revista Nexo.

96 Ares Pons, Roberto: Uruguay: ¿provincia o nación?, Montevideo, Nuevo Mundo, 1967 (1. ${ }^{\text {a }}$ ed. Buenos Aires, Coyoacán, 1961), págs. 19-20. 
nas". ${ }^{97}$ Había algo intangible en el gaucho ("estas cosas más fácil es intuirlas que escribirlas") que despertaron el interés de Ares: su individualismo antiestablishment, su afán de libertad, su capacidad de seguir fielmente una causa motivadora... Un protorrevolucionario, simbólicamente operativo en los años 60: "De nosotros depende, finalmente, que [la herencia del gaucho] constituya una simiente luminosa o un espectro perturbador". ${ }^{8}$

Sin hacer pausas significativas para el estudio de las cuestiones propiamente productivas, Ares ingresaba directamente a la consideración del proceso artiguista. Y lo hacía en términos inequívocos: "Un mito no es una mentira; es una verdad que se expresa simbólicamente. Cuando un hombre se transforma en mito, por lo común su personalidad histórica real no alcanza la proyección magnificada que el mito le confiere. [...] Nosotros podemos dar gracias a Dios porque nuestro mito originario se halla firmemente arraigado en una personalidad real. [...] El examen más severo de la crítica histórica no encuentra en esa roca [José Artigas] ninguna grieta peligrosa". ${ }^{99} \mathrm{Y}$ a mayor abundamiento, agregaba que "en Artigas est[aba] el germen de todas las soluciones nacionales", ${ }^{100}$ lo que incluía por supuesto el remedio a los problemas rurales del país. ¿Qué elementos destacaba Ares del programa agrario artiguista? "El 'Reglamento [...] inspirado en la política de población del Coloniaje, [...] y regido por una concepción del derecho de propiedad con matices comunitarios, anterior al liberalismo contemporáneo", y gracias al cual "aquellos que habían hecho posible la patria [...] la habrían sostenido [si el caudillo hubiera alcanzado sus metas] con su trabajo productivo", configuraba en la década de 1960 "una Reforma Agraria técnicamente perfecta, cuyos lineamientos pueden aún servir de base para cualquier programa similar en nuestros días". ${ }^{101}$ Para Ares, era perentorio recoger las banderas de 1815 en la tarea de liberar al país, y para ello proponía la construcción de esta suerte de neoartiguismo capaz de "cerra[r] el ciclo de las divisas tradicionales cuya superación ya se vislumbra[ba]". La certidumbre de que una nueva fuerza política estaba en gestación y lograría clausurar la extensa etapa de gobiernos blancos y colorados, contaba según esta visión con un aliado impar, "un solo Mito hábil para el cumplimiento de esa función de nuestra historia y él se personifica en

97 Ares Pons, Roberto: Uruguay..., págs. 13-14. Subrayado de Ares.

98 Ares Pons, Roberto: Uruguay..., págs. 15-17.

99 Ares Pons, Roberto: Uruguay..., págs. 24-25.

100 Ares Pons, Roberto: Uruguay..., pág. 26.

101 Ares Pons, Roberto: Uruguay..., pág. 27. Subrayado mío. 
Artigas. [...] Con ese signo nos incorporaremos al segundo acto de la Revolución Hispanoamericana". ${ }^{102}$

En la misma línea interpretativa, Historia de los Orientales, de Carlos Machado $^{103}$ abundó mucho menos todavía en los matices. Ensayo muy difundido (hasta el presente, en que continúa siendo reeditado), identificó tres sectores en la sociedad colonial: alto, medio y bajo, apuntando que "la contradicción mayor y más intensa" de aquella sociedad se encerraba en "el latifundismo por un lado; pequeños y medianos propietarios y ocupantes de tierras por otro", para concluir sin mayores especificaciones que "en ese marco se produjo la revolución". ${ }^{104}$

Así las cosas, los bandos se definieron con sencillez y naturalidad luego de 1811: "a favor [de la revolución], la campaña. Los gauchos, [...] también los 'ocupantes' amenazados por el desalojo, [...] más los terratenientes, enfrentados al monopolismo". ${ }^{105}$ Agrupados los habitantes del campo detrás de Artigas, el proceso se radicalizó hasta alcanzar su punto culminante en 1815, cuando se aprobó el Reglamento de Tierras ("una 'reforma agraria', como decimos hoy"). ${ }^{106}$ Diferenciándose de otros enunciados revisionistas, y más allá de destacar — como toda la izquierda - que con la aplicación de aquellas disposiciones "los más infelices" serían "los más privilegiados", Machado subrayó el carácter contemporizador, parcialmente al menos, del Reglamento, expresión de un antilatifundismo selectivo: "la reforma [...] salvaguardó la propiedad de grandes estancieros artiguistas (el estado mayor). En tal aspecto, el Reglamento [fue] una transacción entre los hacendados y los comandantes". ${ }^{107}$ Avenencia que fue más lejos, con consecuencias para el mapa social de aquel mundo agrario en tanto no se extendió a los negros esclavos el beneficio de convertirse en propietarios y productores: "aquí se manif[estó] la carencia mayor dentro del pensamiento social del artiguismo: no [fue] abolicionista; los negros y los zambos t[enía]n que ser libres para ser agraciados en el repartimiento". ${ }^{108}$

Pero de todos los planteos revisionistas, sin duda el más estrechamente ligado a una praxis política definida fue el de otro dirigente socia-

102 Ares Pons, Roberto: Uruguay..., págs. 119-120.

103 Docente, periodista (colaboró en varios medios y fue director del diario Epoca) y militante por largo tiempo del Partido Socialista (cuyo Comité Ejecutivo integró antes de la dictadura).

104 Machado, Carlos: Historia de los Orientales, tomo 1, Montevideo, EBO, 1986 (1. a ed. 1972), pág. 18.

105 Machado: Historia..., págs. 42-43.

106 Machado: Historia..., pág. 69.

107 Machado: Historia...

108 Machado: Historia..., pág. 70. 
lista, el ya mencionado Vivián Trías. ${ }^{109}$ Fue uno de los primeros (y sin dudas, uno de los principales) promotores de la reformulación en clave izquierdista de la historia oriental de los siglos XVIII y XIX, ${ }^{110}$ a partir de la necesidad, proclamada y defendida en todo trance, de elaborar una propuesta de "socialismo nacional". Planteó sus inquietudes agraristas en varios textos; en uno de ellos, Las Montoneras y el Imperio Británico, refiriéndose a esta cuestión y su estado en tiempos coloniales, estampó una de las más acabadas muestras de esa visión histórica para la cual los conflictos de ayer seguían siendo, con algunos cambios (aunque no los suficientes como para volver invisibles, ni mucho menos, las huellas del pasado), los que marcaban el rumbo de las luchas presentes. Una muestra: citando el famoso informe de Azara sobre el estado de la campaña, decía Trías que "estos elocuentes conceptos desnudan la sórdida oposición entre los modestos y medianos productores que arriesgaban la aventura de colonizar un medio hostil y difícil y los ricos terratenientes [...]. Este encuentro de intereses [...] recorre como una hebra de un solo color toda la historia nacional. Lo reencontraremos en los alzamientos montoneros de casi todo el siglo XIX y, en nuestros días, se renueva con la conocida denominación de 'botudos' y 'galerudos'.". ${ }^{111}$

Para inclinar la balanza en favor del sector más desfavorecido, "las muchedumbres que se alzaron en el 11", ${ }^{112}$ se confeccionó y aprobó el Reglamento de 1815. Recogiendo "las enseñanzas recibidas de Félix de Azara cuando lo acompañó en la colonización del Batovî" diez años antes de iniciarse la revolución, ${ }^{113}$ Artigas echaba las bases para la superación "de la situación anárquica de la campaña, el matreraje, la condición marginal del gaucho, el dominio de la oligarquía latifundista". Cabe destacar

109 Fue docente de historia y filosofía, parlamentario y secretario general del Partido Socialista, con una importante labor en medios de prensa (fundamentalmente en $\mathrm{El} \mathrm{Sol}$, órgano oficial de su partido).

110 Carlos Real de Azúa señaló en un provocador artículo publicado al conmemorarse los 150 años de la aprobación del Reglamento de Tierras (en el que el brillante ensayista mostraba por entonces una abierta simpatía hacia el revisionismo histórico), que Trías y Machado "han sido [...] auténticos 'rara avis' entre los estudiosos de nuestra historia en su preocupación por los problemas fundamentales del pasado uruguayo [y] quienes han señalado con más certeza las implicaciones sociales de las revueltas montoneras". Ver Real de Azúa, Carlos: "Varias hipótesis sobre el peonaje", en Epoca, Montevideo, 10/9/1965, pág. 10.

111 Trías, Vivián: Las Montoneras y el Imperio Británico, Montevideo, Ediciones Uruguay, 1961, pág. 35 .

112 Trías: Las Montoneras..., pág. 43.

113 Trías: Las Montoneras... Machado afirmaba que las influencias habían marchado en sentido inverso; "Artigas [...] influyó sobre Azara, no al revés”. Machado: Historia..., pág. 68. 
que el enfoque de Trías sobre el surgimiento y consolidación del agrarismo artiguista se modificó a lo largo de los años, asignando al ideario reformista del caudillo un protagonismo cada vez mayor y más precoz. En este trabajo de 1961 planteaba que el artiguismo, como movimiento con una determinada visión de los problemas de la Banda Oriental (incluyendo el de la tierra, como uno más de aquellos asuntos) fue "madurando" entre la "Redota" (la marcha hacia el Ayuí de 1811, al levantarse el primer sitio a Montevideo) y la segunda invasión portuguesa de $1816 .{ }^{114}$ Algunos años más tarde, en 1966, sería algo más enfático: "el caudillo y la revolución fueron [a partir de 1811] los factores aglutinantes vinculados a la cuestión de las tierras y de los ganados". ${ }^{115}$ Ya en 1970 atribuiría a la cuestión agraria la absoluta primacía en la misma génesis del movimiento: "la Revolución Oriental de 1811 nació con una definición agraria nítida". ${ }^{116}$

Se detuvo especialmente en cuatro artículos del Reglamento de 1815: el sexto (que establecía las condiciones exigibles a los candidatos al beneficio de la tierra, y contenía el tantas veces citado principio de favorecer a "los más infelices"), el séptimo (una ampliación del anterior), el undécimo (sobre la obligatoriedad de construir "rancho y dos corrales" en un plazo de dos meses) y el décimosegundo, "los terrenos repartibles son todos aquellos de emigrados, malos europeos y peores americanos que hasta la fecha no se hallan indultado por el Jefe de la Provincia para poseer sus antiguas propiedades".

De ello, y de otras ideas contenidas en el reglamento aduanero aprobado pocos días antes de expedirse el de tierras, Trías deducía que se estaba "muy lejos del liberalismo económico a outrance sostenido por la oligarquía unitaria". Léase una transcripción sin adaptar los tiempos verbales: "Artigas concibe un Estado que regula el comercio, protege la industria doméstica, reparte tierras". Trías proyectaba una imagen de Artigas en la que el caudillo concebía un aparato estatal intervencionista en áreas estratégicas, que sería además "instrumento popular para forjar la independencia y el progreso." ${ }^{117}$ En definitiva, este autor proponía una interpretación que sugiere que Artigas hubiera convalidado, de haber podido hacerlo, los

114 Trías: Las Montoneras..., pág. 42.

115 Trías, Vivián: "De las tradiciones artiguistas al ejército nacional y popular", en Epoca, 22/6/1966, pág. 9 .

116 Trías, Vivián: "Nasser: marxismo y caudillismo", en Moreira, Neiva: El Nasserismo y la revolución del Tercer Mundo, Montevideo, EBO, 1970, pág. 247.

117 Trías: "Nasser..., pág. 44. 
proyectos políticos levantados por la izquierda en los años 60, que serían a su vez la base del programa del Frente Amplio en 1971. ${ }^{118}$ Confrontando este pasaje del texto de Trías con el plan de gobierno de la coalición de izquierda que habría de fundarse diez años después, se encuentra una casi perfecta línea de continuidad. ${ }^{119}$

Desde ámbitos "extraacadémicos" provinieron algunos planteos formulados por lo que podría denominarse "frecuentadores" de la Historia, dicho esto no en sentido peyorativo en tanto las cuestiones de método no les fueron ajenas (aunque el dominio de las mismas pudiera no ser completo). Uno de los exponentes más llamativos de este inorgánico grupo fue Esteban Campal. Aunque no ha sido considerado un revisionista, bien puede incluírsele en esta categoría si nos atenemos a la metodología de trabajo, las bases teóricas más o menos evidentes de su propuesta y la clase de interpretaciones a las que arribó a partir de una formación —aspecto que sí lo diferencia de otros nombres considerados en este apartado- eminentemente ajena al quehacer historiográfico-docente. ${ }^{120}$

En su más importante obra, ${ }^{121}$ sintetizó el perfil económico-social de la ocupación de la Banda Oriental durante la colonia con una breve frase: "el trasplante de la Mesta". A la manera de España, donde una organización de importantes propietarios acumuló "grandes extensiones de tierra" destinada a proveer pasturas a "las célebres ovejas merinas [quedando] la agricultura [...] totalmente arruinada", en el Plata tuvo lugar una abierta y desigual lucha "de la ganadería cimarrona [propia del latifundio] contra la agricultura y la ganadería estable de una sola suerte de estancia". ${ }^{122}$ En esta

118 Desde este punto de vista, el planteo de Trías guardó absoluta coherencia a lo largo de toda su obra. Se lee en otro pasaje: "Hoy descubrimos, mejor que nunca, que el artiguismo es un programa. [...] La clase obrera uruguaya ha tomado la bandera y vanguardiza la lucha de siempre. [...] Se dispone a conquistar la Patria Grande". Trías: "Nasser...", pág. 169.

119 El 26 de marzo de 1971, en el primer acto público de esta fuerza política, su presidente el Gral. Líber Seregni pronunció un discurso en el que señaló que se debía "romper los tres pilares básicos de la oligarquía", para lo cual "los tres objetivos, [...] no independientes entre sí [serían] reforma agraria, nacionalización de la banca, nacionalización del comercio exterior". Un dato más: aquella exposición terminó con esta frase: "Padre Artigas: aquí está otra vez tu pueblo; te evoca con emoción y con devoción [y] te dice otra vez, como el Patria Vieja, iguíanos, Padre Artigas!". Seregni, Líber: "No nos dejaremos trampear nuestro destino", en El Popular, Montevideo, 27/3/1971, pág. 4.

120 Ingeniero Agrónomo, radicado en el interior del país (Paysandú), fue columnista de varios medios de prensa y frecuentó los temas de la historia rural rioplatense, en especial desde el punto de vista de la producción. Durante la Presidencia de Andrés Martínez Trueba (1950-1952) fundó una colonia ganadera, a la que bautizó "José Artigas" en explícito homenaje (según el propio Campal) al Reglamento de Tierras de 1815. En 1971 formó parte del equipo de asesores que rodearon a Seregni.

121 Campal, Esteban: Hombres, tierras y ganados, Montevideo, Arca, 1967.

122 Campal: Hombres..., pág. 66. 
sencilla ecuación se sintetizó la evolución económica de la campaña. Ciertas soluciones ensayadas por altos funcionarios españoles le parecieron también muy viables. El pensamiento de un representante del reformismo borbónico en el Plata, Félix de Azara, deslumbró a Campal, quien en otra de sus obras afirmaría que la Memoria sobre el estado rural del Río de la Plata, del ilustrado aragonés "significó para mí una revelación, una verdad que no requería verificación. [...] El diagnóstico de Azara era acertado y su proyecto excelente". ${ }^{123}$

No hizo un examen exhaustivo de la sociedad rural colonial, sino más bien del proceso de concentración de la tierra en manos de unos pocos individuos, destacando cómo ese fenómeno favoreció el estallido revolucionario y la incorporación de los paisanos al bando artiguista. Precisamente, en cuanto a la distinción entre "paisanos" y "gauchos" (en la que básicamente, aparecen los primeros como un sector más significativo - por sus aportes sociales, económicos y políticos- que los segundos), distinción que también interesara a Ares Pons, Campal redujo a su mínima expresión la trascendencia del gaucho, figura que al momento del balance dejaba un saldo muy poco favorable. "El paisano y el gaucho [resumía] poco tienen que ver entre sí; y no fue el gaucho, por cierto, salvo contadísimas excepciones, quien luchó por liberar esta tierra, sino el criollo de origen español y también los misioneros". Recordaba Campal que Artigas, cuyos dichos y actos en este como en muchos otros puntos se convirtieron en medida de valor (tanto para él como, en general, para toda la izquierda), se refirió a sus seguidores como "esos infelices paisanos [mientras que en su correspondencia] jamás [...] mencion[ó] al gaucho, a quien ya es tiempo de reducir a su verdadera estatura histórica y social". ${ }^{24}$

Tampoco en este libro (cuyo título, por otra parte, deja lugar a pocas dudas sobre los contenidos) hay mayores referencias al papel de la agricultura. Más allá de alguna referencia al carácter fundacional de la obra Observaciones sobre agricultura de Manuel Pérez Castellano, también Campal enfatizó en el carácter montevideano de la agricultura colonial, aliada estratégica de lo que llama "ganadería organizada", por oposición al gran latifundio cimarrón. "Nuestra agricultura y la ganadería organi-

123 Campal, Esteban: Azara y su legado al Uruguay, Montevideo, EBO, 1969, pág. 6.

124 Campal: Hombres..., pág. 53. 
zada [apuntó Campal, en alusión a los primeros habitantes de la campaña montevideana], tienen su cuna en el Miguelete y Pando". ${ }^{125}$

\section{3) La aproximación del marxismo}

Los representantes más notorios de la historiografía marxista, un equipo conformado por Lucía Sala, Julio Rodríguez y Nelson de la Torre, ${ }^{126}$ a los que se sumaría más tarde Rosa Alonso, emprendieron una ambiciosa investigación sobre el pasado colonial y revolucionario. En 1967 publicaron los primeros resultados de ese programa de estudios, dos obras que habrían de producir un fuerte impacto en la comunidad historiográfica: Evolución económica de la Banda Oriental y Estructura económico-social de la colonia. Constituía un primer esfuerzo metódico por aplicar sobre la realidad histórica colonial oriental un modelo de análisis marxista, sobre la base de una intensa labor de exploración en archivos. Esta característica es sin duda uno de sus méritos mayores, y uno de los elementos que más aleja estos trabajos de la pura reinterpretación más o menos lúcida de fuentes ya éditas, a la que sistemáticamente recurrió una nutrida camada de ensayistas.

A su modo, dibujaron eficazmente la articulación y contraposición de intereses entre las diferentes capas de la sociedad colonial, en especial aquellas más vinculadas con la producción agropecuaria. Pero la necesidad (impuesta por el marco teórico escogido) de definir la formación económico-social en estudio a partir de modelos concebidos en el contexto europeo, no siempre logró sortear el peligro de las rigideces. Una de ellas es la que deriva del uso del concepto "precapitalismo" con el que definen aquella formación. La apelación a esta categoría requiere de muchas puntualiza-

125 Campal: Hombres..., pág. 54. Es significativo, además, el esbozo del continuo primeros colonos - economía productiva - nacionalidad, en lo que parece ser una concesión a la llamada "tesis independentista tradicional" (no precisamente acuñada por la izquierda), según la cual la nación era un elemento ya configurado antes de iniciarse el proceso revolucionario: "aquellos pocos vecinos de Buenos Aires y los colonos canarios [que poblaron Montevideo en sus orígenes] fueron el verdadero núcleo inicial de la nacionalidad oriental. Ignorantes y virtuosos al mismo tiempo, trabajadores incansables y fanáticos de la religión católica, tuvieron desde el principio un gran apego a la nueva tierra, que fecundaron con su esfuerzo, rodeados de penurias y peligros". Campal: Hombres...

126 Formados en el Instituto de Profesores y la Facultad de Humanidades y Ciencias, ejercieron la docencia durante largos años. Vinculados al Partido Comunista, publicaron sus trabajos en "Ediciones Pueblos Unidos", empresa editorial ligada a dicha fuerza. Contaron además con el apoyo explícito de Eugenio Petit Muñoz. 
ciones, en tanto su capacidad explicativa es, por sí sola, demasiado precaria. Entre los ya complejos conceptos de feudalismo y capitalismo la gama intermedia es, qué duda cabe, casi infinita. ${ }^{127}$

Para esta mirada, los intentos de feudalización, como el de Francisco de Alzáibar a mediados del siglo XVIII, resultaron infructuosos porque "había[n] llegado demasiado tarde", ${ }^{128}$ en la medida en que el sistema de reparto adoptado al fundarse la ciudad de Montevideo había establecido la existencia de la "propiedad libre de colonos libres. Sólo existía la obligación de poblar", de suerte que las posibilidades para la propiedad vinculada estaban canceladas desde el inicio. ${ }^{129}$

Los rasgos precapitalistas de este modo de producción se manifestaban con toda nitidez en las prácticas del comercio monopólico, en el surgimiento de los saladeros y fundamentalmente en el proceso de apropiación de tierras, aspecto que atrajo la mayor parte de la atención del equipo. Evolución económica... incursionó en una inédita cartografía del latifundio; una serie de seis mapas buscaba demostrar que a partir de la segunda mitad del siglo XVIII y hasta la revolución, el avance de la gran propiedad en manos de unos pocos individuos fue cercando a las pequeñas y medianas extensiones, y cercenando todas sus posibilidades de desarrollo. El latifundio se impuso entonces por encima de las "islas [de] pequeña y progresiva propiedad", a las que fue "envolviendo en un abrazo asfixiante". Sin embargo, en el incompleto proceso de apropiación de tierras, y en la coexistencia de distintas formaciones económico-sociales, residió lo esencial del carácter precapitalista de aquella estructura. ${ }^{130}$

En ese contexto abundaron los ocupantes precarios junto a los propietarios de pequeña y mediana magnitud (definidos como "elementos progresistas"). De ellos provino la fuerte resistencia al latifundismo, "desmintiendo la leyenda de una plácida 'siesta colonial' y exhibiendo, por el contrario, una ardiente lucha de clases". ${ }^{131}$ En estas líneas se perfilan algunas claves de la lectura que el marxismo hizo de la historia colonial: existencia de una

127 Sin embargo, debe decirse que en comparación con la obra de otros marxistas, la de este equipo está, como bien ha señalado Real de Azúa, mucho menos penetrada por los desajustes que derivan de una transferencia acrítica de la periodización europea a realidades americanas (Real de Azúa: $E l$ Uruguay como reflexión [II], pág. 590).

128 Sala de Tourón, Lucía; Rodríguez, Julio, y De la Torre, Nelson: Evolución económica de la Banda Oriental, Montevideo, EPU, 1967, pág. 23.

129 Sala de Tourón, Rodríguez y De la Torre: Evolución económica..., pág. 18.

130 Sala de Tourón, Rodríguez y De la Torre: Estructura económico-social de la colonia, Montevideo, EPU, 1967, págs. 16-17.

131 Sala de Tourón, Rodríguez y De la Torre: Evolución económica..., págs. 32-37. 
lucha de clases incubada largamente, articulada con el predomino casi absoluto de la economía ganadera, lo que conduciría también en el análisis de estos autores a la escasa valoración de otras formas productivas. Esta sorda lucha de clases condujo a la temprana formación de una oligarquía: "los de abajo sufrieron la tiranía de los señores de la tierra y de la autoridad colonial" ${ }_{132}$ idea que se refuerza con el uso de títulos como "Entrelazamiento de las clases dominantes y formación de una oligarquía", o "El Cabildo se transforma en órgano de expresión de los intereses de las clases dominantes". Sin embargo, los sectores subalternos no fueron capaces de aglutinarse y, en el marco de esa "ardiente" lucha de intereses, solamente aparecieron como "grupos de pequeños propietarios o poseedores opuestos a latifundistas concretos e inclusive grandes propietarios". ${ }^{133}$

Los desheredados, "la mayoría absoluta de la población", ${ }^{134}$ formaron así una "masa heterogénea" llena de contradicciones y sin mayores posibilidades de imprimir un rumbo determinado a la revolución, sino solamente de sumarse a ella: "ni dirigirían la Revolución ni [...] recogerían sus frutos, pero morirían por ella". ${ }^{135}$

Lo que estos historiadores se proponían dejar claramente planteado en esta primera etapa era que, en la dinámica de la lucha por la tierra, más allá de los informes elevados a las autoridades por distintos funcionarios que recomendaban promover políticas de "arreglo de los campos" (repartos de tierras, poblamiento, etc.), aquellas mantuvieron incambiada la situación. Pero esos planes servirían luego "para afirmar la resistencia de los pequeños y medianos hacendados, y formaron un caudal ideológico que nutrió el pensamiento revolucionario cuando [se llevó a cabo la modificación] real y efectiva del sistema de tenencia de la tierra". ${ }^{136}$

Existía una estrecha relación entre el modo de producción imperante y el nivel jerárquico adjudicado a cada elemento dentro del proceso productivo: en la medida en que la estancia de gran extensión fue cercando y ahogando a la pequeña unidad productiva, naturalmente la agricultura no logró desarrollarse plenamente. Más tarde, este factor, junto a otros, provocarían el pasaje masivo de los pequeños productores al movimiento revolucionario. Con todo, partiendo de esta tesis, el mayor interés que manifes-

132 Sala de Tourón, Rodríguez y De la Torre: Evolución económica..., págs. 83-84.

133 Sala de Tourón, Rodríguez y De la Torre: Estructura económico-social..., pág. 116.

134 Sala de Tourón, Rodríguez y De la Torre: Estructura económico-social..., pág. 169.

135 Sala de Tourón, Rodríguez y De la Torre: Estructura económico-social..., pág. 184.

136 Sala de Tourón, Rodríguez y De la Torre: Evolución económica..., págs. 83-84. 
taron por la exploración directa en fuentes documentales les permitió atisbar una realidad más compleja. Pero tampoco lograron eludir todos los convencionalismos.

Una constatación general, la de que "la ganadería predominó absolutamente sobre la agricultura" a pesar de que "durante la colonia casi todos los años se exportaron trigo y harinas - hecho que no siempre sucedió en la época independiente- $[. .] ",.{ }^{137}$ aparecía acompañada de otras que complejizaban más el panorama. Destacaron, junto a los agricultores instalados en la jurisdicción de Montevideo, la presencia de numerosos grupos (algunos de ellos "más o menos acomodados", ${ }^{138}$ y otros subsistiendo a duras penas) en varios puntos al sur del Río Negro, desde las costas del Río Uruguay hasta Rocha.

Pese a semejante diversidad, se sustuvo que "el mercado interior fue muy limitado, ya que en el campo prácticamente no se consumía pan". Sumados a eso las limitaciones técnicas, los problemas del deficiente régimen de ocupación de tierras y los monopolios comerciales, trajeron como consecuencia la debilidad de la producción agrícola colonial, "excepción hecha de algunas chacras y quintas de los alrededores de Montevideo y de regiones no muy alejadas de este centro de comercialización". ${ }^{139}$ Cabría hacer aquí una observación del mismo tenor que la formulada por Barrán y Nahum al criticar la teoría del hambre de tierras: se extiende a todo el territorio de la Banda Oriental un diagnóstico más aplicable al marco de la jurisdicción de Montevideo y algunas zonas aledañas. No se tomó en cuenta, al menos explícitamente, la existencia de otro centro (Buenos Aires) de suma importancia para la región suroeste de la Banda Oriental, mercado con el que además se guardaba una distancia muy inferior (sin mencionar que administrativamente la región de Colonia dependía de la capital virreinal)..$^{40}$

Existían además en esta misma obra otros indicios de que la agricultura no era una actividad estrictamente marginal en aquellas circunstancias.

137 Sala de Tourón, Rodríguez y De la Torre: Estructura económico-social..., pág. 22.

138 Sala de Tourón, Rodríguez y De la Torre: Estructura económico-social..., pág. 132.

139 Sala de Tourón, Rodríguez y De la Torre: Estructura económico-social..., págs. 65-66. Subrayado mío.

140 Gelman: "Producción campesina...”, págs. 43-44. En Buenos Aires existía un mercado consumidor interesante para la producción agrícola coloniense, o por lo menos para su trigo; Juan Carlos Garavaglia ha demostrado que los habitantes de la ciudad y su campaña, "contra lo que quiere una tradición historiográfica particularmente tenaz [...] consumían pan en abundancia". Garavaglia, Juan Carlos: "El pan de cada día: el mercado de trigo en Buenos Aires, 1700-1820", en Boletín del Instituto..., 3. ${ }^{\mathrm{a}}$ serie, n. $^{\circ}$ 4, pág. 16 . Subrayado de Garavaglia. 
Entre los principales productores instalados en el hinterland montevideano, existía "un grupo enriquecido que ha plantado frutales — producción no sujeta a tarifas - y cuyos establecimientos rind[iero]n ingresos de consideración. Provi[niero]n ya de los antiguos pobladores que ha[bía]n hecho fortuna en el comercio o en la ganadería, raramente en las chacras, y que p[odía]n invertir en sus tierras de labranza [...]" ${ }^{141}$ Más allá de que estas fortunas no se hayan originado en la actividad agrícola, ¿por qué motivo numerosas familias ricas de la sociedad montevideana (los Magariños, los Maciel, los Chopitea, los Berro, los Sáenz de Cavia, etc.), que habían experimentado largamente las ventajas de otras actividades económicas, diversificaron sus inversiones apostando a prácticas tan "poco relevantes"? ¿Un caso de "irracionalidad empresarial", simple derroche o un indicio de que efectivamente la economía agrícola podía generar riquezas? $?^{142}$

Las aristas agraristas del ciclo revolucionario fueron estudiadas por este grupo de historiadores en una obra publicada dos años más tarde: $L a$ revolución agraria artiguista (1815-1816). ${ }^{143}$ En el mismo año de aparición de Evolución económica... y Estructura económico-social... vio la luz Artigas, tierra y revolución, ${ }^{144}$ pequeño trabajo que a manera de síntesis anticipatoria presentó los temas que más extensamente abordarían los autores en La revolución... y en Después de Artigas (1820-1836). ${ }^{145}$

Pero antes de revisar el contenido de estos materiales, es necesario abrir un paréntesis para dar cuenta de la existencia de otros abordajes del artiguismo venidos desde filas comunistas. Entre los primeros intentos, los más importantes fueron los de Jesualdo Sosa y Francisco Pintos. El primero de ellos publicaría una biografía novelada, Artigas: del vasallaje a la revolución (1941). Pintos, por su parte, escribió, entre otros libros, De la

141 Sala de Tourón, Rodríguez y De la Torre: Estructura económico-social..., pág. 132.

142 Sería interesante establecer una comparación entre estos propietarios y sus pares de Buenos Aires, ricos comerciantes interesados también en invertir en quintas cercanas a la ciudad, algunas de las cuales reportaron interesantes ingresos. Ver Socolow, Susan: Los mercaderes en el Buenos Aires virreinal: familia y comercio, Buenos Aires, Ediciones de la Flor, 1991, pág. 80.

143 Sala de Tourón, Rodríguez y De la Torre: La revolución artiguista, Montevideo, EPU, 1969. En 1978, la editorial Siglo XXI de México publicó Artigas y su revolución agraria, 1811-1820, una reedición del trabajo original compuesta por una larga introducción a cargo de Lucía Sala (destinada a "ubicar al lector no rioplatense dentro del proceso colonial") y los doce primeros capítulos de la obra de 1969 que integraban "El proceso de la revolución agraria", primera parte de La revolución agraria artiguista. No se publicó en la edición mexicana la segunda parte, "Geografía de la revolución agraria". 144 Sala de Tourón, Rodríguez y De la Torre: Artigas, tierra y revolución, Montevideo, Arca, 1967. Para este trabajo se ha consultado la segunda edición (Arca, 1971).

145 Sala de Tourón, Rodríguez y De la Torre: Después de Artigas (1820-1836), Montevideo, EPU, 1972. 
Dominación Española a la Guerra Grande (1942), en el que presentaba uno de los primeros análisis de la historia del país desde la perspectiva del materialismo histórico. ${ }^{146}$ Aunque su fecha de publicación los coloca fuera de los límites establecidos para esta tarea, nótese que se trata de muy tempranos antecedentes de acercamientos marxistas a Artigas como personaje histórico de relevancia. Pero detengámonos en el Artigas, de Eugenio Gómez, publicado casi dos décadas antes de los trabajos de Sala, Rodríguez y De la Torre.

Escrito en el marco de los homenajes tributados a Artigas en el centenario de su muerte, este pequeño libro $^{147}$ es un material interesante por varios motivos. En primer lugar, por la sistemática marginación de que ha sido objeto, inclusive entre los propios comunistas, aunque esto seguramente guarda estrecha relación con la expulsión de su creador de este partido político a mediados de los años 50. ${ }^{148}$ En segundo lugar, por provenir de alguien que vió en el artiguismo no un objeto de estudio histórico, sino una plataforma de lanzamiento de determinados contenidos del programa partidario. Y en tercer lugar, por tratarse de un escrito que demuestra que el interés de la izquierda por la figura de Artigas se originó mucho antes de ese momento culminante que fue el proceso fundacional del Frente Amplio. ${ }^{149}$

Sin detenerse demasiado en sutilezas, Gómez establecía un nítido paralelismo entre Artigas, "el jefe que se bat[ía] sin descanso por la inde-

146 Una obra carecterizada por su extrema rigidez teórica; desplegando un modelo explicativo en términos de contraposición entre "civilización y barbarie" (y adoptando así categorías tenazmente defendidas por la historiografía doctoral del siglo XIX e inicios del XX), tomaba partido por la primera variable en tanto el triunfo del "progreso" y la "libertad" favorecerían la implantación del capitalismo, tras el cual (en sucesión ineluctable para la ortodoxia marxista) vendría el socialismo. Carlos Real de Azúa embistió contra esta visión reductora del proceso histórico rioplatense en El patriciado uruguayo, Montevideo, EBO, 1981 (1. ${ }^{\text {a }}$ ed. Asir, 1961), págs. 129-132.

147 Gomez, Eugenio: Artigas, Montevideo, EPU, 1950.

148 Gómez fue uno de los principales dirigentes comunistas desde la década de 1920. Estalinista a carta cabal, ocupó el cargo de secretario general del partido desde 1937 y fue diputado durante varias legislaturas. Acusado de nepotismo (favoreciendo a su hijo en la estructura partidaria), de practicar el culto a su persona y de dirigir el partido con criterio autoritario, fue expulsado violentamente en 1955, hecho que (más allá de los fundamentos de tales acusaciones) se inscribió en la correntada antiestalinista que desde el $20{ }^{\circ}$ Congreso del Partido Comunista soviético afectó al marxismo en todo el mundo.

149 Dos investigadores del Departamento de Historiología de la Facultad de Humanidades y Ciencias de la Educación, Alex Borucki y Cecilia Robilotti, se encuentran estudiando la importancia de la reivindicación de Artigas en el discurso fundacional de esta coalición izquierdista (1970-1971). Véase un avance de investigación en Borucki, Alex, y Robilotti, Cecilia: La reafirmación del artiguismo en el discurso fundacional del Frente Amplio, ponencia ante las Jornadas de Historiografía Rioplatense, Instituto de Investigaciones Históricas “Dr. Emilio Ravignani” (UBA), Buenos Aires, 20 y 21 de noviembre de 2002 . 
pendencia [...], quien exig[ía] respeto al extranjero poderoso, [...] el caudillo del Exodo, que un[ía] a todo un pueblo, [...] el realizador revolucionario que decret[ó] la confiscación de la tierra de los opresores extranjeros y los vendepatrias nativos", y el Partido Comunista uruguayo, "que lucha[ba] contra el imperialismo y la opresión nacional, que combat[ía] las imposiciones monstruosas del imperialismo yanqui [y] sus planes colonizadores, [...] que lucha[ba] por la tierra, el pan y la libertad de su pueblo". ${ }^{150}$

Si el partido proponía a comienzos de la década de 1950 que el estatal Instituto de Colonización distribuyera toda su cartera de tierras entre los aspirantes a trabajar en ellas, se debía a que de esa forma "se continua[ría] la obra de Artigas, [quien] dispon[ía] repartir entre los hombres del pueblo la tierra de los opresores del pueblo y los traidores nacionales". Con una irrefutable vocación por el uso (y el abuso) político de unos datos históricos mínimamente elaborados, el planteo avanzaba velozmente hacia la supresión casi completa de las fronteras entre pasado y presente. Gómez afirmaba que "inspirándose en el pensamiento de Artigas" el partido propuso durante la guerra recién terminada "expropia[r] las tierras de los terratenientes nazis y entregarlas a los campesinos y peones". ${ }^{151} \mathrm{Y}$ así como Artigas "en su tiempo ordenó repartir tierras", el partido sostenía en 1950 la necesidad de imitar aquella reforma, comenzando en ese mismo instante, para concluir la obra revolucionaria en el momento en que "la clase obrera y el pueblo tom[as]en en sus manos el poder y estable[cier]an una República Popular Democrática". Y como corolario de esta argumentación, la comprobación de su validez, venida desde muy lejos: "lo justo de esta aspiración sobre la tierra y lo ventajoso de la misma, está probado en los hechos por las Repúblicas Socialistas Soviéticas, donde la tierra está en manos de quienes la trabajan". ${ }^{152}$

Con Eugenio Gómez, un sector del marxismo uruguayo elaboraba una imagen "a medida" del Artigas-líder agrarista, que tanto se invocaba para justificar la supresión de los latifundios en manos de simpatizantes del nazismo - reales o presuntos-, como para extender un certificado de aprobación a la política agraria del régimen soviético. ${ }^{153}$ Además, esta exal-

150 Gómez: Artigas..., págs. 11-12.

151 Gómez: Artigas..., págs. 25-26.

152 Gómez: Artigas..., pág. 30.

153 Si se observa lo que ocurría en la otra fuerza marxista con cierta importancia en el escenario uruguayo, el Partido Socialista, se advierte que quien fuera su principal dirigente hasta inicios de los años 60, Emilio Frugoni, no se interesó mayormente por el rescate histórico del artiguismo. Una extensa conferencia sobre el tema "Reforma Agraria" que pronunciara en 1943, contenía numerosas 
tación del héroe que conducía a las masas hacia un determinado objetivo común puede ser interpretada en dos niveles: por una parte, como reflejo (para algunos, tal vez inesperado) de las concepciones historiográficas liberales y su preferencia por los grandes personajes sobre los enfoques marxistas; en otro plano, más pedestre, como una forma ensayada por Gómez, conductor con mano férrea de un partido "de masas", de autocelebrarse mientras ensalzaba las glorias del caudillo evocado.

Un cuarto de siglo más tarde, el equipo formado por Sala, Rodríguez y De la Torre reemprendió el recorrido bajo otras condiciones. Aquella temprana preocupación del comunismo uruguayo por ligar la lucha del artiguismo a las necesidades de reforma agraria del presente, manifestadas tempranamente por Gómez, no decaería sino que más bien cobró fuerza creciente. Se verificó, sí, una aproximación a este núcleo temático por otras vías, a las que se quiso dotar de un carácter más "científico".

La revolución... tuvo, como se ha dicho, un pequeño anticipo en Artigas: tierra y revolución, aunque éste cubre el lapso 1811-1820 mientras que el de 1969 se centraría en el bienio 1815-1816. El primero de estos trabajos se abría con una acerba crítica a la historiografía liberal y al revisionismo, ambas definidas como "historia metafísica [...] idealista y antidialéctica", cuyos exponentes "habla[ba]n de unitarios y federales como verdades intangibles, eternamente válidas e iguales a sí mismas [...]. Como decía Marx de Proudhon, en la historia ven la lucha entre lo 'bueno' y lo 'malo' en vez de deslumbrarse ante la dialéctica". ${ }^{154} \mathrm{Al}$ reseñar los principales hechos del proceso revolucionario de 1811-1820, lo hacían estableciendo las contradicciones entre Buenos Aires y las provincias, destacando en éstas su carácter revolucionario (especialmente en el litoral) y su defensa del proteccionismo. En ese marco, se presentaba una Montevideo que era ciertamente sede de los intereses colonialistas, pero no solamente de ellos; entre los principales comerciantes, hacendados y saladeristas encontraron "actitudes que [fueron] desde la cerrada oposición [a la revolución] pasando por la dudosa situación [de otros individuos] hasta la franca adhe-

\footnotetext{
referencias a Lamartine, Juan B. Justo, Henry George, Otto Bauer, etc., pero ni una sola referencia al programa agrario artiguista. Véase "Conferencia del Dr. Emilio Frugoni, dictada el 10 de setiembre de 1943”, en Furgón, Emilio; Rubio, Antonio; Gonzalez Vidart, Arturo, y Martínez Trueba, Andrés: Sobre la Reforma Agraria en el Uruguay, Montevideo, Publicaciones del Club Banco Hipotecario, 1944. Obsérvese la fecha en que fue realizado el evento: 10 de setiembre, aniversario de la aprobación del Reglamento de 1815. Ni aún así Frugoni hizo alusión al hecho. 154 Sala de Tourón, Rodríguez y De la Torre: tierra..., pág. 7.
} 
sión a la Revolución [de otros, no muy numerosos pero cuya postura quedó documentada]". ${ }^{155}$

Junto a Artigas se alzó un sector muy heterogéneo: grandes, medianos y pequeños propietarios u ocupantes de tierras, agricultores, comerciantes, con "las grandes masas de peones, gauchos, indios y negros escapados a los españoles", 156 alianza que fue diluyéndose a medida que el proceso se radicalizó y "los más privilegiados" fueron desertando, especialmente luego de 1816, debido a tres causas básicas: "una política cada vez más radicalizada del artiguismo, [...] las diferencias en materia de táctica, [y] el temor a la destrucción de la riqueza ganadera cuya recuperación se había iniciado en el año $15 " .{ }^{157}$ En este punto se registraba otra diferencia con el revisionismo, que consideraba a Artigas un reformador nato, mientras que este equipo sostuvo que el reformismo artiguista fue un elemento en permanente construcción y profundización a lo largo de esa década. ${ }^{158}$

Pero las diferencias con otras corrientes de izquierda se atenuaron al momento de calificar el proyecto agrario y las cualidades de su promotor. En Artigas... se consolidó una nítida tendencia al panegírico insinuada en los tramos finales de los dos libros sobre el período colonial, la cual se haría mucho más abierta en La revolución..., adoptando giros decididamente hiperbólicos. Se postuló una valoración general del agrarismo en estos términos: "en el Reglamento [...] se enc[ontrab]an reflejadas ante todo, las ideas del hombre más avezado y conocedor de los problemas de la campaña y de las aspiraciones de las masas campesinas trabajadoras [en un] cuerpo de disposiciones sabio, realista y perfectamente consustanciado con la realidad social y material sobre la que se aplicaba." 159

Al plantear las características de la lucha (que era "de clases") entre los revolucionarios y la oligarquía, los autores evaluaron las actitudes de los protagonistas de esos hechos adjudicándoles una lógica de razonamiento propia de épocas muy posteriores. Señalaron, por ejemplo, que los grandes hacendados que aceptaban interesadamente ocupantes precarios en sus dominios "sabían lo que hacían cuando despreciaban la renta capitalista para obtener el 'señorío' sobre varios subordinados". ${ }^{160}$

155 Sala de Tourón, Rodríguez y De la Torre: tierra..., pág. 30.

156 Sala de Tourón, Rodríguez y De la Torre: tierra..., pág. 36.

157 Sala de Tourón, Rodríguez y De la Torre: tierra..., pág. 46.

158 Destacaron la inconveniencia de "atribuirle una metafísica y prenatal vocación político-

social”. Sala de Tourón, Rodríguez y De la Torre: tierra..., pág. 64.

159 Sala de Tourón, Rodríguez y De la Torre: tierra..., pág. 55.

160 Sala de Tourón, Rodríguez y De la Torre: tierra..., pág. 62. 
Aunque es incuestionable que se trataba de un grupo poderoso que defendía sus privilegios y buscaba incrementarlos, ¿estaban realmente estos hacendados rioplatenses de comienzos del siglo XIX en posición de hacer lecturas de la coyuntura que ameritaran interpretaciones de este tenor? Apuntaron además que de no haberse producido la invasión portuguesa "Artigas pudo haber triunfado contra las tendencias contrarrevolucionarias y precapitalistas", ${ }^{161}$ en lo que constituyó una aproximación (no la única por cierto, y siempre peligrosa además) a la llamada "historia virtual”, que elabora sus especulaciones con preguntas del tipo "¿qué habría sucedido si...?".

Recordemos que al comienzo de esta obra se fustigaba al pensamiento metafísico, idealista y antihistórico del mitrismo y el revisionismo. Una crítica en muchos aspectos compartible, pero que no puso a este equipo a resguardo de otro tipo de inconvenientes, como esa cierta proclividad al reduccionismo causal visible en algunos pasajes, derivado del ya apuntado apego a un modelo explicativo y relacionado con lo que parecía ser un deseo de ver a la naciente comunidad nacional (conducida por Artigas) en el camino hacia la revolución socialista, cuyo sendero necesariamente debía atravesar el ciclo capitalista. El afán por destacar el carácter burgués de la revolución artiguista se inscribe en esta concepción: "Artigas, al fin de cuentas, era - y debía serlo- el mejor defensor de la propiedad privada burguesa, y el peor enemigo de la propiedad señorial, simple hábitat de un mundo de subordinaciones personales". Y reafirmaban: "el camino artiguista consolidaba la propiedad —en esos días lo más revolucionario--". ${ }^{162}$

Interesa señalar que para este enfoque el Reglamento pretendía "civilizar" a la campaña y su población, no en el sentido sarmientino de suprimir física y abruptamente la existencia del gauchaje, sino transformándolo en útil elemento de trabajo y productor de riquezas. Artigas, pues, luchó "contra la herencia que el mundo colonial legó a las condiciones sociales de las masas pobres", a las que "sería tonto y demagógico pretender caracterizar [...] como una suerte de masa seráfica e incontaminada". Puede decirse que tales preocupaciones fueron la versión historiográfica de inquietudes políticas muy acuciantes para toda la izquierda uruguaya de aquellos años: el hecho (difícilmente reversible) de que las tendencias

161 Sala de Tourón, Rodríguez y De la Torre: tierra..., pág. 92.

162 Sala de Tourón, Rodríguez y De la Torre: tierra..., pág. 96. 
populistas de derecha (particularmente fuertes en el gobernante Partido Colorado) eran apoyadas en medida nada menor por los sectores populares, particularmente el lumpen. ${ }^{163}$ Artigas, siglo y medio antes, ya habría entrevisto la importancia de suprimir el "desclasamiento de amplios sectores de los desheredados de la campaña", que caído el orden colonial no eran otra cosa que carne de contrarrevolución. ${ }^{164}$

Se ha dicho más arriba que en La revolución... la propensión al tratamiento elogioso del objeto de estudio se acentuó. La apertura, a cargo (como el anterior Evolución económica...) de Eugenio Petit Muñoz, ${ }^{165}$ fue muy elocuente: "los autores, seguros de sí mismos en la justicia de su posición, adjetivan y señalan a menudo con virulencia a los elementos del bando contrario [al artiguismo], y lo hacen con incisivo y mordiente lenguaje, que no han cuidado de depurar porque [es] prueba de la espontaneidad, [hija] del gesto de instintiva repugnancia en que se traducía su indignada visión de [la] realidad maloliente de las sucias maniobras en que se complotaba la reacción en sus intentos de hacer imposible el triunfo de los ideales justicieros de Artigas y de las masas explotadas que éstos venían a redimir". ${ }^{166} \mathrm{La}$ advertencia al lector escrita por los propios Sala, Rodríguez y De la Torre no era menos ilustrativa, y se abrió con esta frase: "tenemos la honra de presentar el fenómeno más sublime de nuestra Patria Vieja". ${ }^{167}$ No deja de ser sorprendente que un enfoque historiográfico que se autopercibía "científico" partiera de tales premisas, más cercanas de lo conveniente a una postura epistemológica según la cual la investigación histórica es simplemente una operación de rescate y difu-

163 Un documento de la Juventud Demócrata Cristiana (íntegrante del Frente Amplio) se preguntaba con cierto desasosiego en 1972: “¿por qué la clase trabajadora [...] no votó masivamente al Frente [en las elecciones de 1971]? ¿Por qué los marginados, que viven en condiciones infrahumanas, apoyaron al oficialismo, directo responsable de su situación?”. Un problema complejo sin duda, que para ser resuelto requería, entre otras medidas, "detener el avance del fascismo [...] inmovilizándolo en la propia base social, dando una eficaz lucha ideológica". Archivo de Propaganda Política (APP), Fondo Mena Segarra, 1972, caja 5, fs. 52v y 53 (Juventud Demócrata Cristiana (JDC): "Un Camino para la Revolución Uruguaya"). Agradezco a los profesores Alex Borucki y Cecilia Robilotti el haberme sugerido la consulta de este material.

164 JDC: "Un Camino...", pág. 93.

165 Nacido en 1894, abogado y poseedor de una vasta cultura, publicó varios estudios sobre el artiguismo y tuvo una extensa trayectoria docente en el Instituto Magisterial, y en las facultades de Derecho y Humanidades; fue en esta última director de su Instituto de Investigaciones Históricas hasta ser destituído en 1974. Enfrentado a dos dictaduras (la de Gabriel Terra en 1933, y la iniciada cuarenta años más tarde), militó activamente contra el fascismo y fue uno de los fundadores del Frente Amplio entre 1970 y 1971.

166 Sala de Tourón, Rodríguez y De la Torre: La revolución..., pág. 11.

167 Sala de Tourón, Rodríguez y De la Torre: La revolución..., pág. 12. 
sión de una verdad preexistente y (tal vez malévolamente) mantenida en la oscuridad. ${ }^{168}$

El propio Petit Muñoz, en otro pasaje del citado prólogo, señalaba que junto a los aspectos sociales y económicos del Reglamento era necesario en 1969 destacar otros, "patrióticos y políticos", hasta entonces descuidados porque (escribió sugestivamente) "lo consideré obvio". ${ }^{169}$ En forma casi coetánea, Petit afirmaría en un breve escrito que el Reglamento "puso en obra principios, no igualados en la Revolución de América, de justicia social [...]", y por ello calificó al documento de "asombroso". ${ }^{170}$ Elogios que, en otro lugar, Petit hiciera extensivos a los aspectos estrictamente jurídicos del Reglamento, considerándolo "una ley [...] singularmente completa en sus previsiones, no solo de fondo sino de forma". Paradójicamente, el prudente llamamiento a lectores e investigadores para que situaran a Artigas "dentro de su circunstancia histórica total y verdadera, [...] lo único científicamente admisible" en estudios históricos, iba seguido de la absoluta certidumbre de que el resultado de un enfoque de ese tipo no sería otro que el acopio de elementos para "medir los alientos proféticos en que, adelantándose a su época, [Artigas] avizor[ó] ideales de justicia que sus contemporáneos no alcanzaron". ${ }^{171}$

La revolución... se sostuvo, como las demás obras de Sala, Rodríguez y De la Torre, en una intensa exploración en archivos, que en lo metodológico continuó ampliando la brecha entre la labor de este equipo y la ensayística. A partir de allí, intentaron reconstruir el proceso de formación de una conciencia agrarista en Artigas y su entorno, la elaboración del Reglamento, su aplicación final, y los resultados producidos, describiendo lo que llamaron la "geografía de la Revolución" (análisis de seis

168 Jesús Bentancourt Díaz, profesor de Filosofía de la Historia y jefe del Departamento de Historiología de la Facultad de Humanidades y Ciencias hasta 1973, escribió en referencia a la historiografía del romanticismo que su "afán de distribuir palmas y castigos obedecía a un propósito moralista, o político, o de cualquier otra naturaleza. Pero no científico. Causaba a la Historia un perjuicio irremediable”. Bentancourt Díaz, Jesús: ¿Qué es la Historia?, Montevideo, Departamento de Publicaciones de la FHCE-UDELAR, 1992, pág. 75. ¿Hasta qué punto una observación de esta índole no alcanza también a ciertos planteos formulados en La revolución agraria artiguista (1815-1816)?

169 En Sala de Tourón, Rodríguez y De la Torre: La revolución..., pág. 7. Subrayado mío.

170 Petit Muñoz, Eugenio: Artigas y la función pública, Montevideo, Biblioteca de la Junta Departamental, 1970, pág. 40.

171 Petit Muñoz, Eugenio: Artigas y la administración de justicia, Montevideo, Suprema Corte de Justicia, 1964, págs. 30 y 34. Vale destacar (como una muestra más del especialísimo clima en el que todo lo concerniente al artiguismo tenía lugar en aquel Uruguay) que en el mensaje introductorio a este breve texto, la Suprema Corte de Justicia anunciaba a sus funcionarios — a quienes el trabajo de Petit estaba dirigido_ - que se trataba de "un panegírico relativo a la persona del Prócer" (pág. 1). 
jurisdicciones del territorio oriental, y lo sucedido en cada una de ellas con la aplicación de esta reforma agraria). Dos elementos fueron particularmente atendidos: la marcha del proceso revolucionario, desde una inicial lucha de amplia participación social (interviniendo, aunque en grados diversos, todos los sectores de la población) hasta la final radicalización socio-política, resultado de la cual fue la propia existencia del Reglamento; y la contestación a este fenómeno, dada por la deserción de los representantes de las clases altas de filas revolucionarias, su resistencia a la reforma agraria y la alianza con los invasores portugueses para cerrar la etapa insurreccional, que en esta óptica adquirió la forma de un verdadero "furor campesino".

La difundida interpretación de que hacia fines del período colonial se registraba un consistente fenómeno de hambre de tierras alcanzó su culminación en este libro. Aprobado el Reglamento, y en marcha los mecanismos de fraccionamiento y concesión, "los paisanos pobres se atropellaban solicitando la suerte concedida"; ${ }^{172}$ estos habitantes del campo, "los paisanos pobres que realizaron la revolución más profunda del contorno americano", ${ }^{173}$ empujaron hacia la radicalización de la revolución. Por su parte, el caudillo (al que llaman —aludiendo a su cuartel general a orillas del Uruguay - "águila de Purificación", en lo que puede advertirse una comparación no demasiado velada con Napoleón) ${ }^{174}$ interpretaba sagazmente las demandas de "las masas" conduciendo dicho proceso. El punto culminante de este curso de acción fue la aprobación y posterior aplicación del Reglamento, que conoció su momento más espectacular (antes del frenazo impuesto por la invasión portuguesa) en "noviembre de 1815 [...], el mes volcánico de la revolución agraria". ${ }^{175}$

Pero además, a medida que este proceso se fue profundizando trajo consigo el surgimiento de otro componente: una "conciencia nacional" encarnada en las clases bajas de la Banda. Las "clases pobres y miserables del campo [aportaron] la conducción y [el] tono de la revolución nacional de independencia", al tiempo que se hacía cada día más evidente y profunda "la mutua relación e influencia nacida entre Artigas y las masas pobres" de la provincia. ${ }^{176}$

172 Sala de Tourón, Rodríguez y De la Torre: La revolución..., pág. 136.

173 Sala de Tourón, Rodríguez y De la Torre: La revolución..., pág. 142.

174 Sala de Tourón, Rodríguez y De la Torre: La revolución..., pág. 63.

175 Sala de Tourón, Rodríguez y De la Torre: La revolución..., pág. 215.

176 Sala de Tourón, Rodríguez y De la Torre: La revolución..., pág. 191. 
Acerca de este aspecto y de la implantación geográfica de la revolución agraria, es muy visible el corte espacial fundamentalmente local que estos investigadores dieron a su trabajo; más allá de las alusiones (que fueron muchas) a la interacción del artiguismo con otras provincias, fue básicamente dentro del territorio de la Provincia Oriental donde se desarrolló el relato. Dado que el libro se basó fundamentalmente en el estudio de la aprobación y aplicación del Reglamento de Tierras (pensado para y aplicado en la Provincia), no era esta una opción desencaminada. Sin embargo, hay un hecho significativo: para la confección de algunos mapas ${ }^{177}$ en los que se graficó la marcha de los procesos de fraccionamiento y ocupación de tierras, se tomó como base no el territorio (mal delimitado entonces) de la antigua Provincia, sino el que corresponde a la actual superficie de nuestro país. ¿Estaba el Uruguay de 1969 prefigurado en las luchas por la tierra de 1815 ?

La siguiente publicación de este equipo, Después de Artigas, se detendría en el análisis de las consecuencias de la derrota del artiguismo (18201836). Aunque se dedicó al examen de un período posterior, su lectura es un complemento eficaz de los anteriores textos, pues allí se completa la cronología: surgimiento, desarrollo, auge y caída del artiguismo, y camino abierto a las concepciones más retardatarias en la sociedad oriental, representadas por los dos partidos tradicionales. A caballo del análisis histórico de estos fenómenos, construyeron su versión del discurso acrático, sostenido en una radical defensa del artiguismo y en la crítica tenaz de sus enemigos, de los que los dirigentes de los partidos Colorado y Nacional eran herederos directos. A estos efectos, vale recordar un fragmento de la parte inicial de Después...: "en resumen, aparato colonial portugués, clases dominantes criollo-españolas, masas artiguistas: he aquí las tres grandes fuerzas que pugnaban en la Banda Oriental cisplatina". Derrotada la revolución, se consolidó una "estructura social semifeudal" en la que se articularon lazos de dependencia personal y solidaridades de clase, relaciones que "teñidas de uno u otro contenido histórico-concreto tuvieron una suficiente solidez como para perdurar en la época independiente hasta cristalizar en los partidos de York y Lancaster, de borgoñones y armagnacs que dieron al Uruguay décimonono su rostro reconocible: Blancos y Colorados". ${ }^{178}$ y 270.

177 Verlos en Sala de Tourón, Rodríguez y De la Torre: La revolución..., págs. 45, 65, 141, 203

178 Sala de Tourón, Rodríguez y De la Torre: La revolución...; Después..., pág. 10. 
No faltó, por supuesto, la respuesta de los aludidos, cuyo signo (siguiendo el esquema propuesto) fue definidamente encrático. Observemos un ejemplo: en el marco del bicentenario del nacimiento de Artigas, la prensa afín al Partido Nacional (gobernante por entonces) replicó a la izquierda, que reivindicaba para sí el carácter continuador de la lucha del artiguismo, y específicamente a los comunistas, que el olvido "de la trayectoria del patricio que nos dio la nacionalidad por quienes comulgan con orientaciones extranjeras, no nos preocupa. Pero que los servidores del Kremlin pretendan tomarlo como estandarte, nos parece una irrespetuosidad hacia la memoria del prócer". ${ }^{179}$

\section{Algunos comentarios finales}

El uso político (no simplemente partidario) de la figura de José Artigas ha sido y sigue siendo uno de los elementos culturalmente más significativos en el Uruguay. Claro está, como ya se ha señalado, no todos los actores han llevado adelante esta reivindicación de idéntica forma. En lo que a la izquierda se refiere, el destacar los elementos revolucionarios y populares de aquel proceso desempeñó una doble función. Por una parte, dotó a unas fuerzas tradicionalmente apegadas a concepciones teóricas de matriz "foránea" (el socialismo, el comunismo, la democracia cristiana) de una nueva mística de enraizamiento en lo local, entroncada con la verdadera esencia nacional. Pero además, la izquierda se autopercibió como única fuerza verdaderamente continuadora de las inconclusas luchas de los días de la revolución de independencia, y única capaz de traducir en realidades aquellos proyectos, estrategia discursiva desarrollada a partir de 1950, intensificada a lo largo de la década siguiente y significativamente amplificada en la coyuntura de la fundación del Frente Amplio, 1970-1971. ${ }^{180}$

La cuestión agraria fue en aquellos días uno de los revulsivos más notorios en todo el continente americano; en el Uruguay el tratamiento de este factor por parte de la izquierda tuvo sus peculiaridades, en tanto no existía aquí (y en verdad, no ha existido nunca) un campesinado lo suficientemente poderoso como para forzar, por la vía que fuese, una reforma

179 “Negando a Artigas", en El País, Montevideo, 18/6/1964, pág. 4.

180 Borucki y Robilotti, La reafirmación del artiguismo... 
agraria más o menos amplia. No hay duda de que los problemas del latifundio, del estancamiento productivo y del empobrecimiento progresivo de los habitantes del campo existían y en magnitudes importantes. No obstante, evalúense desde otra perspectiva dos hechos nada casuales: 1) la izquierda tuvo por aquellos años un electorado fundamentalmente montevideano, proceso que ha comenzado a variar, y con lentitud manifiesta, en tiempos muy recientes; 2) más significativamente todavía, repárese en la circunstancia de que el movimiento tupamaro fue un caso (más bien atípico en el mundo subdesarrollado) de guerrilla urbana con escasos apoyos en el campo, siendo que una de sus banderas principales era precisamente la expropiación de los latifundios. ${ }^{181} \mathrm{Y}$ sin embargo, nuestra historia ofrecía lo que para la izquierda era el paradigma de revolución independentista teñida de un agrarismo impar. Curiosamente, el mito liberal de la "excepción uruguaya" tan fustigado por la izquierda, fue de algún modo "reciclado": nuestro privilegio, nuestra marca de distinción, no radicaba en lo que éramos bajo la "siesta liberal" de la primera mitad del siglo XX, sino en lo que habíamos estado a punto de lograr entre 1810 y 1820, y en lo que podíamos llegar a ser de la mano de una izquierda realmente artiguista (o un "artiguismo de izquierda", según se prefiera). Un artiguismo para el balance, y también para diseñar el proyecto.

En ese doble mecanismo de apropiación contestataria (acrática) de la tradición agraria del artiguismo promovido por la izquierda (aglutinante en lo interno; diferenciador en relación con los partidos tradicionales), el rol de la historiografía fue muy importante. ${ }^{182} \mathrm{Y}$ si bien es posible registrar debates entre los distintos autores y corrientes (lo cual dotó a aquel período de una

181 Real de Azúa observó en 1965 que con la escasa magnitud de la población de la campaña, especialmente del movedizo peón rural, también se vinculaba aparentemente "el carácter montevideano y motinero de nuestras querellas civiles desde 1851 hasta los tiempos de Aparicio [Saravia]", en Real de Azúa: "Varias hipótesis...", pág. 10.

182 El presidente del Frente Amplio, Gral. Líber Seregni, destacó en un discurso pronunciado el 19 de junio de 1971, que "en un día como hoy [aniversario del nacimiento de Artigas] es oportuno que todos revisen sus conceptos históricos, que aclaren sus opiniones sobre la historia uruguaya. Una crisis tan profunda como la del Uruguay que vivimos, exige no aceptar ninguna imagen convencional de nuestro pasado [...] Si no reexaminamos el ayer, si no criticamos el ayer, lo dejaremos monopolizado por las tergiversaciones de la oligarquía y estaremos perdiendo nuestra batalla de hoy. [...] Y es un hecho notorio, en razón de los años de relativa satisfacción en que ha vivido el país y que ya son cosa pasada, que los orientales han vivido demasiado desinteresados de su propia historia, porque cuando las cosas andan bien: ¿quién se acuerda del pasado? Pero como hoy resulta evidente que andan mal, interpretar el ayer nos es indispensable para entender la razón de nuestros males. De lo contrario andaríamos a ciegas. Y los ciegos no pueden conducir". Citado por Borucki y Robilotti, La reafirmación del artiguismo..., págs. 7-8. 
característica peculiar, no muy frecuente en otros períodos — anteriores y posteriores - de la historiografía del país) ${ }^{183}$ sin embargo, como se ha visto, los análisis tendieron a coincidir significativamente en determinados aspectos fácilmente perceptibles:

* en general, se privilegió el estudio de los procesos "macro" de apropiación de tierras, formación de grandes latifundios y su enfrentamiento con las "islas" de pequeña y mediana propiedad, en un horizonte económico casi enteramente dominado por la ganadería. Otras actividades económicas (al caso, la agricultura) fueron estudiadas, o apenas mencionadas, como actividades menores de las que se dejó constancia en no pocas ocasiones como un simple hecho anecdótico. ¿Cómo relacionar este aspecto del enfoque historiográfico con el proyecto agrarista de la izquierda en los años 60 y 70 ? Resulta oportuno, una vez más, recordar al Trías de Reforma agraria en el Uruguay: "las condiciones climáticas y otras características de nuestro territorio, hacen prácticamente imposible una agricultura próspera". Y apoyándose en los estudios de Eliseo Salvador Porta y de Carlos Quijano, sentenciaba que "nuestra reforma agraria debe ser, en buena parte, un plan dirigido a estimular y desarrollar, como prioridad y no como exclusividad, la producción ganadera" ${ }^{184}$ ¿Hasta qué punto el proyecto agrario de la izquierda uruguaya incidió sobre la manera de enfocar los temas agrícolas y ganaderos por parte de los historiadores-militantes, o viceversa, hasta dónde las enseñanzas de la historia (y no solamente de la economía, la agronomía o la sociología rural) pautaron la confección de programas de gobierno y proyectos de desarrollo? Es muy difícil calibrarlo con precisión, pero es mucho menos dificultoso conjeturar la existencia de un juego de espejos entre ambos elementos.

* Los enfoques fueron casi exclusivamente panorámicos; poca o nula atención se prestó a los casos particulares, y en este sentido es posible postular la presencia de al menos dos elementos fuertemente determinantes.

183 Hace una década Javier Vázquez D’Elia señalaba, en un artículo de título inquietante "La historiografía uruguaya reciente o el temor a la controversia”, en Revista da História, 1:1, dezembro 1992, algunas de las carencias presentes en la investigación histórica de nuestro país en ese momento. Entre esas observaciones, marcaba la tendencia al "reparto tácito de temas" entre los investigadores, incluyendo problemas y períodos. Contrastando con ello, la historiografía de los años 60 y 70 tomó al agrarismo artiguista (cabe el énfasis, porque el artiguismo como fenómeno político de proyecciones históricas suscitó otros consensos mucho más amplios, y, por qué no, sorprendentes) como asunto recurrente, aunque los niveles de debate entre estos autores no tuvieron, ni mucho menos, la intensidad de las discusiones entre este núcleo y sus pares de treinta, cuarenta o más años antes...

184 Trías, La crisis agraria..., págs. 308-309. 
De un lado, la por entonces (¿solamente por entonces?) débil tradición uruguaya en estudios de "escala reducida". Por otra parte, si de la ligazón natural entre inquietudes políticas e historiografía se trataba, resultaban más apropiados los amplios abordajes de carácter "nacional", capaces de explicar en su conjunto las causas de nuestro atraso y nuestra dependencia, fundamentando la necesidad de un rompimiento con el pasado reciente (el del Uruguay "blanquicolorado") para ir al encuentro de un pasado más remoto y glorioso, y reeditarlo.

* En la interpretación de la izquierda (por lo menos, de una parte muy considerable de ella), el artiguismo y las fuerzas revolucionarias de la década de 1960 estaban empeñados en lo mismo: llevar a cabo una auténtica revolución popular antiimperialista y antioligárquica. El enemigo histórico de la revolución era muy claramente perceptible aún después de que "el republicanismo jacobino de los paisanos" fuera derrotado por la "crueldad latifundista" instalada tras la derrota de Artigas. Un sistema de injusticias y sometimiento al extranjero sostenido por una oligarquía "que ahora [se decía en 1969] comienza a morir". ${ }^{185}$

* Para todos estos análisis el agrarismo artiguista tuvo en su momento de mayor desarrollo, el lapso 1815-1816, y en su elemento central, el Reglamento de Tierras, características revolucionarias únicas que dieron al movimiento un perfil inconfundible en el contexto de la revolución hispanoamericana. Más allá de matices en lo atinente a la valoración de ciertos aspectos políticos del documento (concretamente: distintas posturas acerca de si hubo o no transacción entre Artigas y los grandes hacendados en cuanto a las tierras disponibles, al papel de la agricultura, al tratamiento dado a los negros esclavos), el consenso en torno a las bondades del proyecto desde el punto de vista socioeconómico fue total.

En suma, el examen de los resultados de estos estudios sobre el agrarismo artiguista muestra que por encima de las disensiones existentes se ubicaron unas amplias afinidades, derivadas de la certeza colectiva acerca de lo correcto de la concepción y del carácter eminentemente popular del proyecto de 1815. En palabras recientes de Lucía Sala, para aquellos historiadores se trataba de escribir "una historia que fuera historia del pueblo [por lo cual] íbamos a buscar determinados temas, [porque] el historiador también encuentra lo que busca [y] el tema de la tierra estaba en el país".

185 Sala de Tourón, Rodríguez y De la Torre: Después..., págs. 257-258. 
En ese marco, acota esta investigadora, "los libros fueron bien recibidos pero porque era la época". ${ }^{186}$

Imbricación de inquietudes políticas, de esperanzas propias de aquel presente, e intereses historiográficos explicitada de manera transparente en el siguiente fragmento, escrito por Oscar Bruschera en 1969: "en este nuevo condicionamiento, que impone al país el desafío de su reinserción en el mundo circundante, se yergue, asimismo, compelida por el imperativo de afrontar la clave de su subdesarrollo, la necesaria promoción del agro. Los hechos demuestran la evidencia de las limitaciones uruguayas, el despilfarro y las carencias de su economía agraria, estructurada en función de intereses colonialistas, distorsionada por el latifundio y el minifundio, incapacitada para producir en condiciones de alto rendimiento. También desde este ángulo se rescata la verdad creadora de Artigas, enérgico impulsor de una ley de tierras que concilia un profundo contenido económico con un propósito de justicia social; los acentos humanos y solidarios con el inflexible disciplinamiento en el trabajo y el severo control de la conducta". ${ }^{187}$

186 Entrevista hecha por Sansón, Aproximación a la historiografía marxista..., pág. 10.

187 Bruschera, Óscar: Artigas, Montevideo, Biblioteca de Marcha-Librosur, 1986 (1. a ed. 1969), págs. 50-51. 